\title{
Topic-Focus Articulation in Taqbaylit and Tashelhit Berber
}

\section{Mettouchi, Amina}

John Benjamins

2010

Mettouchi , A \& Fleisch , A 2010 , Topic-Focus Articulation in Taqbaylit and Tashelhit Berber . in I Fiedler \& A Schwarz (eds), The expression of information structure : A documentation of its diversity across Africa. Typological Studies in Language, vol. 91 , John Benjamins, pp. 193-232 . < http://www.benjamins.com/cgi-bin/t_bookview.cgi?bookid=TSL\%2091 >

http://hdl.handle.net/10138/18578

submittedVersion

Downloaded from Helda, University of Helsinki institutional repository.

This is an electronic reprint of the original article.

This reprint may differ from the original in pagination and typographic detail.

Please cite the original version. 


\title{
Topic-Focus Articulation in Taqbaylit and Tashelhit Berber ${ }^{1}$
}

\author{
Amina Mettouchi \\ LLING, Université de Nantes \& Institut Universitaire de France \\ Axel Fleisch \\ University of South Africa, Tshwane
}

This paper deals with the form/function mapping of information structure on word-order in two Berber lects, Taqbaylit (Kabyle) and Tashelhit (Shilha). We claim that the general assumption according to which Berber should be strictly VSO is wrong, and we argue for a more cautious approach, that takes into account language variation inside Berber. We show that pragmatics trigger the emergence of (relatively stable) discourse-configurationality, without giving rise to a $\mathrm{VSO}>\mathrm{SVO}$ shift. We compare Taqbaylit and Tashelhit in terms of information structure and word order variation, and come to the conclusion that, while there is good reason to classify Taqbaylit as discourseconfigurational, Tashelhit is somewhat more restrictive in terms of word order flexibility. We link those characteristics with case-marking: the distinction between free state and annexation state is more clearly a dependency-oriented phenomenon in Taqbaylit, while it corresponds more closely to a subject (or marked nominative) versus absolute case system in Tashelhit.

\section{Introduction}

In Berber, syntactic patterns in which core constituents follow the verb are very common. Berber varieties have therefore often been described as basically VSO or verb-initial languages. It has been claimed that, for pragmatic reasons, verb-initial languages will always provide some syntactic mechanism that results in a different position of the subject with respect to the verb. Indeed, if one looks at data from Berber, it is not uncommon to find syntactic patterns that do not conform to a VSO pattern at all. At the same time, distinct Berber lects turn out to differ considerably with regard to word order variation. The description of information structure, and 
of how topicality and focus are expressed, is therefore an indispensable part of the grammatical analysis of any of these linguistic varieties.

In this regard, a strong claim has been made concerning Taqbaylit Berber (N-Algeria). Mettouchi (2005, 2007, to appear b) argues that the language should be characterised synchronically as discourse-configurational (in the sense of Kiss 1995) rather than by an allegedly basic VSO word order. One of the motivations for the present article was to look at another Berber variety, in this case Tashelhit Berber (S-Morocco), and see whether a similar interpretation seems plausible. If not, one would have to assume significant typological differences within Berber. In this case, these differences should point at the diachronic dimension of information structure, discourse-configurationality and the emergence of varying word order patterns. These are the main topics that we wish to address in the present article.

The phenomenon of pragmatically-motivated word order variation is intrinsically related to two other phenomena that need to be addressed here as well: (a) the question of the argumental status of lexical constituents, the co-referential personal affixes and clitics; and (b) the dependent state marking (='marked nominative', 'subject' or 'integrative' case in other scholars' terminologies) of lexical nouns in certain functions, showing the further peculiarity that case assignment depends on syntactic position. The descriptive sections will deal with these properties in detail, and make clear in what ways this bears on the issue of how word order variation came into being, and how stable it is diachronically.

Our paper is structured into five parts. Following this brief introduction, part 2 presents the framework in which the study is grounded, and illustrates the conventional assumptions about word order in Berber and how they relate to pragmatics, as well as more recent work that has cast doubt on some of these views. Often claims have been made for Berber at large on the basis of a single lect. Apparently, it is often assumed implicitly that syntactic phenomena and pragmatics are broadly similar throughout Berber. We want to turn this into an empirical question rather than take it for granted as a simple a priori presupposition. Therefore, parts 3 and 4 are dedicated to the description of language-specific characteristics of Taqbaylit and Tashelhit respectively. In part 5, we will then proceed to comparison and draw conclusions from shared features, but also, and perhaps even more importantly, from distinctive properties of the two lects under study. This opens a path to a richer understanding of the diachrony of word order variation in Berber.

\section{Views on topic-focus articulation and word order variation in Berber}

\subsection{Topic-focus articulation}

It is widely assumed that languages have syntactic and/or prosodic means to express topic-focus articulation. One of our aims in this article will be to assess whether information structure is reflected by word order variation, and if it is the case, to what 
extent. Many frameworks have built on notions such as rhematicity and thematicity, or focus and topic. We will use Lambrecht's (1994) and Sasse's (1987) definitions of such concepts as focus and the distinction between thetic and categorical statements.

Lambrecht (1994) defines central notions pertinent to information structure in the following way: "A constituent is a topic expression if the proposition expressed by the clause with which it is associated is pragmatically construed as being about the referent of this constituent." In this case, the proposition expresses "information which is relevant to and which increases the addressee's knowledge about this referent", i.e. about the topic (Lambrecht 1994: 131). An antitopical construction is "a construction in which a lexical topic NP is positioned at the end of the clause containing the information about the topic referent." (1994: 202)

"The definition of topic in terms of aboutness and contextual relevance entails that there is an inherent relationship between topic and pragmatic presupposition. Since the topic is the already established 'matter of current concern' about which new information is added in an utterance, for a proposition to be construable as being about a topic referent this referent must evidently be part of the pragmatic presupposition, i.e. it must already be 'under discussion' or otherwise available from the context." (1994: 150)

By 'pragmatic presupposition' Lambrecht understands "[t]he set of propositions lexicogrammatically evoked in a sentence which the speaker assumes the hearer already knows or is ready to take for granted at the time the sentence is uttered", while the pragmatic assertion refers to the "proposition expressed by a sentence which the hearer is expected to know or take for granted as a result of hearing the sentence uttered." (1994: 52) Both notions are important in understanding Lambrecht's characterisation of 'focus' which he describes as the "semantic component of a pragmatically structured proposition whereby the assertion differs from the presupposition." (1994: 213)

"The focus articulations of sentences can be divided into a number of distinct types which correspond to different kinds of pragmatically structured propositions." (1994: 221) "The unmarked subject-predicate (topic-comment) sentence type in [(What did the children do next?) The children went to SCHOOL], in which the predicate is the focus and in which the subject (plus any other topical elements) is in the presupposition, will be said to have predicate-focus structure; the identificational type illustrated in [(Who went to school?) The CHILDREN went to school], in which the focus identifies the missing argument in a presupposed open proposition, will be said to have argument-focus structure; and the event-reporting or presentational sentence type, in which the focus extends over both the subject and the predicate (minus any topical non-subject elements) [(What happened?) The CHILDREN went to SCHOOL], will be said to have sentence-focus structure." (1994:223)

For most practical purposes, Lambrecht's approach ties in neatly with Sasse's distinction between categorical and thetical statements despite certain differences. Lambrecht's propositions in sentence-focus articulation are not exactly co-extensive with Sasse's thetical statements. While for the former the crucial notion is that the subject is in focus together with the predicate (irrespective of other topical elements), 
Sasse argues that there is no distinction between presupposition and assertion in thetical statements. "Thetic utterances may be said to assert the existence of a state of affairs, but they do not predicate it." (Sasse 1987: 556; for more information on Sasse's view, cf. also pp. 571-573)

In addition to the notions illustrated so far, we consider verb-focus a marked variant of predicate-focus by which focus is placed exclusively on the situation denoted by the verb.

Another distinction that we need to draw concerns the notion of contrastiveness. Both topical and focussed elements can receive contrastive emphasis indicated by stress, specific morphosyntactic constructions or, in the case of pronominal topics, simply the fact that an overt pronoun is present. If an assertion contains a contrastively focussed element, this usually implies a notion of surprise or counterexpectation, often used when contradicting a prior statement [(In a restaurant: Jean will have salmon.) (What?), he has ordered LAMB]. A topic is contrastively emphasised if it is selected from among several possible pragmatically presupposed elements [(On the phone: What are you guys doing?) Well, I am preparing dinner; MY FRIEND is still at work].

All those focus-types are expressed in languages through morphology, syntax and/ or prosody. While it is true that there is no strict one-to-one correspondence between a particular sentence type and a particular focus type, one can however study the various word ordering possibilities within a language, together with their prosodic patterns, and see how they map with focus structure.

\subsection{Word order variation}

A common starting-point for discussing word order variation is to assume one word order as basic or least marked. For Berber, it is usually claimed that the verb precedes the subject and any objects (if the core constituents are expressed by full lexical NPs). While this word order is indeed frequent, this observation still needs to be refined. First of all, it must be made clear what is actually understood by "basic" or "unmarked" in connection with the notion of (core) constituent order. For some, the assumption of one basic word order implies that any other constellation of core constituents encountered in the data should be viewed as being derived from the assumed basic VSO order by movement of constituents (cf. Guerssel \& Hale 1987). Others have held views that do not assign such a predominant status to VSO in Berber, although they also speak of VSO as "basic" or "unmarked". Finally, some linguists, following Mithun (1987) question the very notion of basic word order.

Although VSO is often regarded as synchronically basic (and in any case as diachronically primary, even beyond the boundaries of Berber in the larger Afroasiatic family), scholars have usually been aware of the fact that constituent orders other than VSO do occur in the languages under study. Verb-initial languages pose a specific challenge with regard to pragmatics and the structuring of information in the sentence. Opposing views on how pragmatic requirements (such as the distinction of topic and 
comment) are handled by verb-initial languages have been expressed since at least the 1970s. Payne (1995) illustrates them by contrasting Creider (1983) and Longacre (1982).

Creider argues that sentences in verb-initial languages present new information first, while the known information tends to occur at the end of the sentence (Creider 1983). This would be the reverse order of the much more widely attested topic/ comment-organisation as a discourse-relevant syntactic ordering principle in natural languages. Longacre (1982: 484) argues that pragmatic requirements would make sentences with a left-shifted subject possible and necessary, even in the most rigid VSO languages, but he expresses a modified view when dealing with the "peculiar narrative competence of VSO languages" (Longacre 1995: 335).

"In going down the storyline from sentence to sentence, the successive initial verbs introduce one by one new happenings into the story, i.e. actions, motions, cognitive events, speech acts, and contingencies (things which happen to people). This natural foregrounding of the happenings leads to a somewhat opposite structure from the theme-rheme distribution which we have learned to expect in a Prague School 'functional sentence perspective', because in VSO structures the most rhematic elements precede the themes." (ibid.)

He still maintains that left-shifted NPs are necessarily thematic. In a similar vein, Doris Payne, who includes Tashelhit in her article on the typology of word order variation in verb-initial languages, argues that in these languages, topic-comment sequencing is actually much more common than implied by some previous scholars (1995; cf. Creider 1983).

Rather than assuming a reverse order of rheme-theme, the traditional accounts of scholars working on Berber regard word order flexibility as a consequence of topicalising mechanisms that trigger lexical NPs in pre-verbal position, as opposed to those strategies that serve to express new information to the right edge of the clause or sentence. These views are therefore compatible with a functional sentence perspective as paraphrased by Longacre (see above). With regard to alternative constituent orders, it is no surprise that SVO is the most common among them. Pre-verbal full lexical NPs co-referential with the subject marker on the verb are traditionally explained as topicalised subjects. While there is little doubt that fronted NPs are indeed topics, there are a number of open questions and issues to be explored in more detail. It is not the case that there is only one fronting mechanism. Lafkioui (unpublished paper presentation at CALL, Leiden, 29-31 August 2005) has given prosodic evidence for Tarifit that pre-verbal NP constructions fall into different types, although segmentally they look very much alike. This implies that there are probably functionally motivated strategies of different origins. At the same time, an interesting question to pursue would be to look at speaker variation and multilingualism as a factor in word order flexibility. For Tarifit, el Aissati (2001) offers data showing a significant difference in the syntactic patterns as used by younger speakers of Tarifit according to whether 
they live in N-Morocco or in Europe. Yet, this does not tell us by itself whether the differences are due to a direct influence of European contact languages, or to an accentuation of natural tendencies in language contact and multilingual settings.

If we intend to address these questions satisfactorily, certain pre-requisites need to be complied with. Since obviously not all syntactic strategies presenting NPs in pre-verbal positions go back to the same mechanism, functional differences between these strategies will have to be described with great care. Apart from topicalisation, a distinction between new and given information status comes into play, as well as a distinction between pure emphasis and contrast. By contrast we understand the presentation of a constituent in a given context, in which any other referent is ruled out ('she [and not anyone else] did it'; see also 2.1).

While being termed 'basic' or primary, the VS order has been even less studied than SV. To our knowledge, no studies were carried out on the semantic and pragmatic (informational) motivations of the VS order before Mettouchi (2005a). This issue is linked to the somewhat problematic notion of subjecthood and status of other core constituents in Berber. Some authors consider the post-verbal NP as the real subject of the clause (Allaoua 1994), as opposed to the pre-posed topic NP. Others, like Galand (1964) and Chaker (1988), consider it as a lexical specification of the personal affix borne on the verb. This view has been widespread since Galand (1964) in the French school of Berber studies, and it has been inspired by similar hypotheses proposed for Basque (Martinet 1962). Apart from the optionality of the NPs co-referential to affixes or clitics, case-marking patterns in Taqbaylit provide some evidence in favour of such an analysis (cf. Mettouchi 2005).

Irrespective of one's stance with regard to this issue, it should be kept in mind that Berber shows traces of a former stative-active system (Mettouchi 2003b, 2004), and certain constructions have been argued to be characteristic of a split-S system (Aikhenvald 1995), although an alternative analysis could be thought of for the latter. In any case, monolithic notions of subjecthood and pivotal NPs should not simply be presupposed. Their applicability to the NPs under question has to be thoroughly scrutinised in the analysis of any Berber lect. As the following two parts will show, there are significant differences in this regard between Taqbaylit and Tashelhit.

\section{Taqbaylit}

Taqbaylit is spoken in the North of Algeria by four million speakers (five if we include immigrant communities in Europe and North America). The variety from which all examples are taken is a Western variety, spoken in the village of Ait Ikhlef, in the geographical center of the present extension of the dialectal zone of Taqbaylit. All examples are taken from recordings of spontaneous speech, in various genres, collected between 1993 and 2005².

In this part, we will expose two claims that play an essential role in the description of focus structure in Taqbaylit, presented in Mettouchi (2005; to appear a; 2007): (a) 
that Taqbaylit is synchronically a pronominal argument language, where syntactic structure is based on dependency relations that involve pronominal affixes and clitics, and case-marking ('annexation state'); (b) that the ordering of lexical NPs is constrained by information structure, which in Taqbaylit involves a marked distinction between sentence focus and predicate focus.

\subsection{Taqbaylit as a pronominal-argument language}

Morphosyntactically, the verbal stem is completed by an obligatory personal affix which represents the main participant of the event or state. The traditional analysis (Galand 1964), reinforced by recent studies (Mettouchi to appear a) posits the personal affix as the subject. The sequence formed by the affix (ye-) and the stem ( $\check{c} \check{c}$, perfective) is a complete basic utterance.

(1) $y e-\check{c} c \breve{a}$

$3 \mathrm{sm}_{\mathrm{SUBJ}}-\mathrm{eat}_{\mathrm{PERF}}$

'he ate/has eaten'

This sequence can be followed by clitics (dative and accusative), and a proximal or distal particle ${ }^{3}$. The order of clitics is rigid.

$\begin{array}{llll}\text { te-fka } & =\text { yas } & =\text { ten } & i D \\ 3 \mathrm{sf}_{\mathrm{SUBJ}} \text { give }_{\mathrm{PERF}} & =3 \mathrm{~s}_{\mathrm{DAT}} & 3 \mathrm{pm}_{\mathrm{ACC}} & \text { PROX }\end{array}$ 'she gave them to him/her'

The string of clitics is attached to the head of the clause. The default head (indicative, realis, positive main clause) is the verb. Otherwise, preverbal (irrealis, progressive, negative, relative) particles take on head status. Lexical NPs never appear between the particle and the verb, they are either before the particle (with 'free state' (absolutive (unmarked)) case-marking), or after the verb (with 'annexation state' (integrative (marked)) case-marking). The following example is the irrealis version of example (2):

(3) a. taqcict ad =as =ten $=i D$ te-fk girl.FS IRR $=3 \mathrm{~s}_{\mathrm{DAT}}=3 \mathrm{pm}_{\mathrm{ACC}}=\mathrm{PROX} \quad 3 \mathrm{sf}_{\mathrm{SUBJ}}-$ - $^{-\mathrm{give}_{\mathrm{AOR}}}$ 'The girl will give them to him/her'
b. $a d=a s=t e n=i D$ te-fk teqcict $\mathrm{IRR}=3 \mathrm{~s}_{\mathrm{DAT}}=3 \mathrm{pm}_{\mathrm{ACC}}=\mathrm{PROX} \quad 3 \mathrm{sf}_{\mathrm{SUBJ}}-$ give $_{\mathrm{AOR}}$ girl.AS 'The girl will give them to him/her'

Personal affixes and clitics can be coreferential to lexical NPs or independent pronouns, which we consider as adjuncts, following Jelinek's (1984) analysis of pronominal argument languages. In the previous example for instance, teqcict is coreferential to 
the personal affix te-, which is the grammatical subject of the sentence.

One of the arguments supporting this analysis is the fact that there are long stretches of discourse where only the personal affix appears. The narrative sequence below ${ }^{4}$ shows on which basis the reference-tracking system of personal affixes is organized. Affixes that are not directly coindexed with an NP or pronoun are framed.

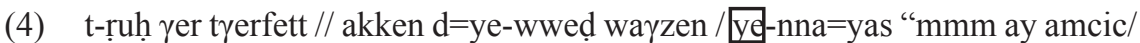

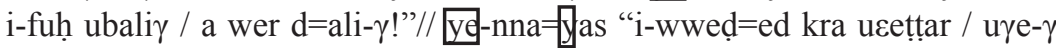

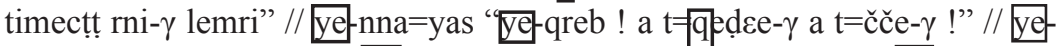

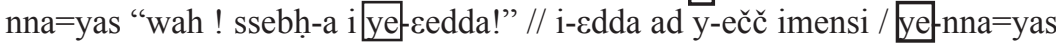
"ay amcic / ay ye-lha imensi n wass-a!"

She climbed in the attic. As soon as the ogre arrived, he told him "mmm, cat, he stinks olive marc, beware I should have to go upstairs!". He told him "he arrived some pedlar, I bought a comb and a mirror". Hetold him ' he is close, I will catch him and eat him!". He told him "Oh only this morning did he come!". He started he ate supper. He told him "O cat, how good today's supper is!". 5

This strategy is frequent in languages where personal affix markers are considered to be the true arguments of the verb, such as Seneca, a native American language of New York State, thus described by Chafe (1994: 149):

"[I]nstead of being used to express given information, the Seneca prefixes refer to the core participants of events and states - referents that are obligatorily included in an event or state idea. When a Seneca speaker chooses to categorize an event or state in a particular way, that categorization dictates the presence of one, two, or occasionally three participants which are obligatorily expressed with a pronominal prefix. Their activation cost is irrelevant. Whereas English uses pronouns to verbalize given referents, Seneca uses pronominal prefixes to verbalize core participants."

In Taqbaylit for instance, a number of verbs are ambitransitive, and it is the number of expressed arguments (affixes and clitics) which indicate its valency, the form of the verb remaining the same. Other arguments in favour of the interpretation of personal affixes and clitics as core arguments are given in Mettouchi (2005; to appear a). The personal affix represents the primary core argument of the verb. Accusative clitics tend to be associated with patients and dative clitics with recipients or beneficiaries (for a more in-depth discussion of the syntactic and semantic values of personal affixes and clitics, see Mettouchi 2007). 


\subsection{Focus structure in Taqbaylit Berber}

Having posited the personal affixes and clitics as the core arguments of the verb ${ }^{6}$, we will now present the most frequent configurations encountered in Taqbaylit narratives and conversations, in relation to the information structure they convey. The basic utterance is referred to as pa-V (personal affix-verb), and NPs coreferential to the personal affix and accusative and dative clitics are labelled $\mathrm{NP}_{\mathrm{S}}$ (coreferent to the personal affix), $\mathrm{NP}_{\mathrm{A}}$ (coreferent to the accusative clitic) and $\mathrm{NP}_{\mathrm{D}}$ (coreferent to the dative clitic), lexical direct objects being labelled $\mathrm{O}$.

$\left(1433^{\text {rd }}\right.$ person verbal predications $\left.{ }^{7}\right)$ :

\begin{tabular}{|c|c|c|c|c|}
\hline $\begin{array}{ll}\text { pa-V } & \mathrm{N} \\
(\text { ("VS") } & \end{array}$ & $\begin{array}{ll}\mathrm{NP}_{\mathrm{S}} & \text { pa-V } \\
\text { ("SV") } & \end{array}$ & pa-V & $\mathrm{NP}_{\mathrm{A}} \mathbf{p a}-\mathrm{V}-\mathbf{C} \mathbf{L}_{\mathrm{ACC}}$ (“OV') & pa-V O ("VO") \\
\hline$[42 \%]$ & $25 \quad[\mathbf{1 7 . 5 \%}]$ & $35 \quad[24.5 \%]$ & $1 \quad[0.5 \%]$ & $22 \quad[\mathbf{1 5 . 5 \%}]$ \\
\hline
\end{tabular}

Table 1: Word-order variation in conversation (cf. Mettouchi to appear a, 2007)

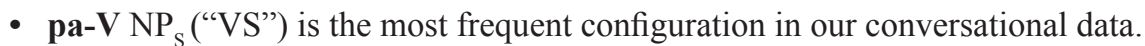

- The pa-V (+clitics) configuration amounts to almost one quarter of the predications, $40 \%$ if we include pa-V O. This in itself might cast doubt on the heuristic value of word order combination comparisons involving only full NPs.

- The $\mathrm{NP}_{\mathrm{S}}$ pa-V ("SV") word order is less frequent than pa-V $\mathrm{NP}_{\mathrm{S}}$ ("VS") in conversation $(17.5 \%)$.

- Objects tend to follow the verb.

(110 $3^{\text {rd }}$ person verbal predications)

\begin{tabular}{|c|c|c|c|c|}
\hline pa-V NP ${ }_{S}$ ("VS") & $\mathrm{NP}_{\mathrm{S}} \mathbf{p a - V}$ ("SV") & pa-V & $\mathrm{NP}_{\mathrm{A}} \mathbf{p a}-\mathbf{V}=\mathrm{CL}_{\mathrm{ACC}}$ & pa-V O \\
\hline $20 \quad[\mathbf{1 8 \%}]$ & $15 \quad[\mathbf{1 4 \%}]$ & {$[46 \%]$} & $3 \quad[3 \%]$ & {$[19 \%]$} \\
\hline
\end{tabular}

Table 2: Comparison with word-order variation in narration

(Mettouchi 2005)

- This time, almost half of the predications involve only a minimal utterance, composed of a verb and its obligatory personal affix. If we include $\mathrm{NP}_{\mathrm{A}}$ pa-V$\mathbf{C L}_{\mathrm{ACC}}$ and pa-V O, the percentage reaches almost $70 \%$.

- As for the $\mathrm{NP}_{\mathrm{S}}$ pa-V ("SV") and pa-V NP ("VS") configurations, they are almost equivalently distributed, and they amount, together, to a third of the data.

- Here as well, objects tend to follow the verb. 
Those various configurations correspond to different focus structures, as we will now show.

\subsubsection{Predicate focus}

Predicate focus is the unmarked focus-structure associated to the topic-comment construction. It involves a topic, and a proposition construed as being about this referent. The topic can be expressed by a lexical XP, or by a pronominal affix. The first case is not so frequent in Taqbaylit, because as we argued, the true argument is not the lexical XP but the pronominal affix. Role and reference are separately encoded: XPs coreferential to personal affixes or clitics are primarily referential, whereas role is encoded by the obligatory personal markers. This results in two different constructions, which we will term continuative and discontinuative predicate focus. Continuative predicate focus only involves sentences where no lexical NP is expressed, while discontinuative predicate focus involves sentences where a lexical NP is expressed.

\subsubsection{Continuative predicate focus}

This type of focus is expressed by pa-V or pa-VO configurations. These basic sentences are very frequent in Taqbaylit, especially in narratives. Their relative scarcity in conversation $(24,5 \%$, as opposed to narratives, $46 \%$ ) can be explained by the fluctuating nature of conversation, where referents are more liable to change according to the flow of consciousness, and therefore have to be introduced as lexical NPs.

In our conversation data, there are however numerous cases when pa-V(O) configurations are met. Most of the time, the referent can be traced back to the previous utterance, as in (5).

(5) amek amar $d$ aparti ye-rebh-en / amek ur=ay

$$
\begin{aligned}
& \text { how if COP party.FS 3sm-prosper- }{ }_{\text {PERF.PRTCP }} \text { how NEG=1p } \\
& \text { ye-tteawan ara? } \\
& {\text { 3 } \mathrm{sm}_{\text {SUBJ }} \text {-help }}_{\text {IMPF }} \text { POSTNEG? } \\
& \text { 'How is it, if it's a prosperous party, how is it that it doesn't help us?' }
\end{aligned}
$$

In ye-ttcawan, the personal prefix refers to aparti ye-rebh-en (a prosperous party). We can notice that the relationship with the lexical NP is rather of co-reference than agreement, the referent being part of the previous clause.

Sometimes the referent does not even appear in the previous context, and can only be inferred. After a passage in which speaker A explains her hardships as a widow, she utters the following sentence: 


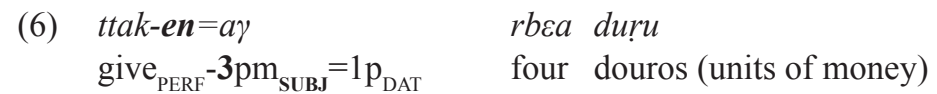

'They give us four douros [i.e. a very small amount of money] (and that's all).'

The referent of the third person plural suffix never appears before or after the clause. Only the context, speaker A's laments about her status as a widow and the problems she had educating her children, as well as her criticism of society, leads us to interpret the referent of the suffix as 'the government'. This example shows that the personal affix has a certain degree of autonomy, and that it is difficult to consider it as a mere agreement marker.

In narratives, as shown in 3.1 , the pa-V or pa-VO configuration indicates continuing topics, i.e. predications in which the protagonists or referents have already been introduced in the previous discourse.

\subsubsection{Discontinuative predicate focus}

This type of focus is expressed by $\mathbf{N P}_{\mathbf{S}} \mathbf{p a}-\mathbf{V}$ ("SV") or $\mathbf{N P}_{\mathbf{A}} \mathbf{p a}-\mathbf{V}=\mathbf{C L}_{\mathbf{A C C}}$ ("OV") configurations.

In narratives, discontinuative predicate focus is used when there is a topic shift, or when two referents are contrasted. In (7), the mother and a friend of hers are holding the strings of the loom, while the little girl is going back and forth with the shuttle. The preposed "subjects", two independent pronouns, are contrasted to each other.

(7) Nettat d yiwet .tff-ent tisegra/nettat she and one hold PERF $-3 \mathrm{pf}_{\mathrm{SUBJ}}$ strings.FS/she la $=$ sent te-zzazzal. $\mathrm{CONC}=3 \mathrm{pf}_{\mathrm{DAT}} \quad 3$ sf-run $_{\text {CAUSIMPF }}$ 'She [the mother] and one (of her friends) held the strings, (while) she [the little girl] ran to and fro.'

In numerous cases, what is marked is an articulation in the narration, an epsiode boundary. This is not related to newness of referent, since in the following case, takurt 'the shuttle' had just been mentioned. But we clearly have a shift in the narration: from then on, the little girl will follow the shuttle, never see her mother again, and live a number of adventures.

$\begin{array}{lllll}\text { (8) Armi } & d & \text { yiwen ubrid/te-zwi } & =y a s & \text { yemm-as } \\ \text { until } & \mathrm{COP} & \text { one time. } \mathrm{AS} / 3 \mathrm{sf}_{\mathrm{SUBJ}} \text { - }^{-} \text {wist }_{\mathrm{PERF}} & =3 \mathrm{~s}_{\mathrm{DAT}} & \text { mother-her }\end{array}$ 
takurt deg ufus// Takurt te-grareb

shuttle.FS from hand.AS//shuttle.FS $3 \mathrm{sf}_{\text {SUBJ }}$-roll_away $_{\text {PERF }}$

'Until the moment when the mother twisted the shuttle from the little girl's hand. The shuttle rolled away.'

In conversational data, the various functions encountered in the course of the analysis can be subsumed under two main categories, namely contrast between referents, and selection of a referent as the basis of an assessment.

Most examples of preverbal subjects occur in contrastive contexts. In (9), after having described the hardships that she has lived through as a widow, Speaker A expresses her wishes.

(9) ne-ttmenni incallah, sya ar zzat/ xas nekni $1 \mathrm{p}_{\text {SUBJ }}-$ hope $_{\text {IMPF }}$ please-God, from-here to forward//even_if we

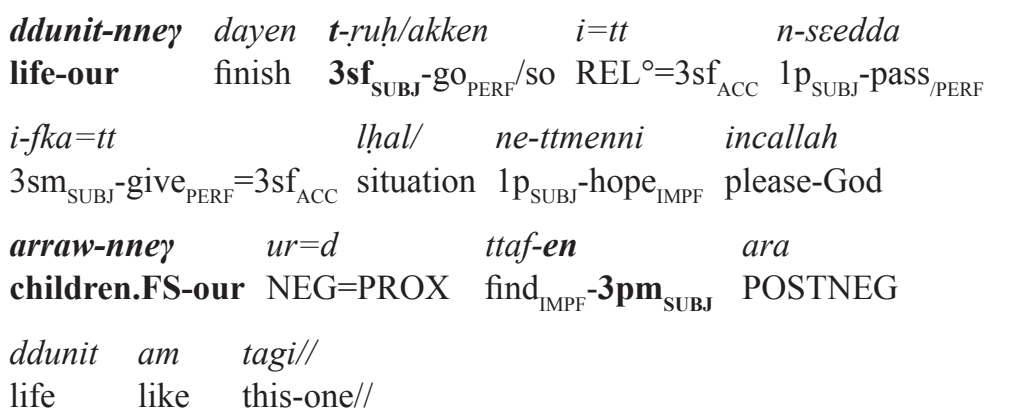

'We hope please God, (that) from now on, even if our life is now gone, we lived it the way it was imposed to us, we hope please God (that) our children will not lead a life like this.'

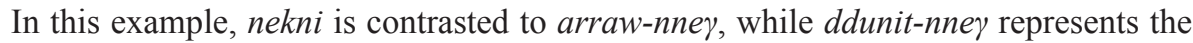
referent around which this part of the conversation revolves: the speaker hopes that life will be different for her children than it has been for her. Topics are not necessarily coreferential to subject affixes, as is shown in this example by the independent pronoun nekni, which here is echoed by the possessive affix -nne $\gamma$. The topical NP is ddunit-nne $\gamma$, and is coreferent to the subject affix of the verb 'go'. The contrast is not between ddunit-nney ('our life') and arraw-nney ('our children'), but it is between nekni ('we') and arraw-nner ('our children') about the referent ddunit ('life'), which is the subtopic at this point of the conversation.

Sometimes, the contrast is not so strong, but we have an enumeration of referents to which different predicates are attributed, as in (10), where speaker B describes the state of her family:

(10) nekni yiwend amexlul/wayed meskin ye-mmut d amjahed/ we one COP fool.FS/other poor $3 \mathbf{s m}_{\text {SUBJ }}-$ die $_{\text {PERF }}$ COP martyr.FS / 
$\begin{array}{lllll}\text { tamyart } & y-u \gamma & \text { lhal } & \boldsymbol{t} \text {-ruh } & z i k \\ \text { old_woman.FS } & 3 \mathrm{sm}_{\mathrm{SUBJ}}-\text { take }_{\mathrm{PERF}} & \text { situation } & \mathbf{3 s f}_{\mathrm{SUBJ}}-\mathrm{go}_{\mathrm{PERF}} & \text { early }\end{array}$

'as far as we were concerned, one was a dimwit, the other, poor man was killed in the independence war; (as for) my mother-in-law, it happened that she died early'

In other cases, configurations involving topicalized subjects appear when the referent is inferable, and taken as a starting-point for a justification, a commentary, an assessment. In (11), after having expressed her wonder at the fact that the government is not helping her family despite her nine children, Speaker B mentions her husband ('the father'), who has participated in the independence war, and been jailed for that. This is an additional factor that should have implied government help.

(11) amek amar $d \quad$ aparti ye-rebh-en/amek $u r=a \gamma$ how if COP party.FS prosper PERF.PRTCP $/$ how $N E G=1 p_{\text {ACC }}$

ye-tteawan ara? baba-s

$3 \mathrm{sm}_{\mathrm{SUBJ}}-$ help $_{\text {IMPF }}$ POSTNEG father-3s $\mathbf{s}_{\text {POSS }}$

ye-ttwahbes/baba-s ye-xdem

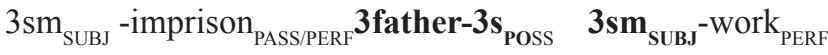

tewralakken ye-nna Reḅbi d lhaq/yernu ur

revolution/so $3 \mathrm{sm}_{\mathrm{SUBJ}}-\mathrm{Say}_{\mathrm{PERF}}$ God COP truth/moreover NEG

ye-sci ara kra $n$ diplôme

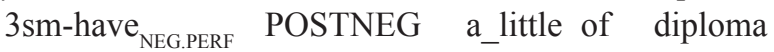

'How is it, if it's a prosperous party, how is it that it doesn't help us? the father got imprisoned, the father participated in the revolution, God is a witness to that, and moreover, he doesn't have the least diploma.'

Babas is related to the previous context morphosyntactically (it is marked by a possessive) and pragmatically: government help is often dependent on the martyr status of the breadwinner (usually the father) during the independence war. However, other possibilities were also inferable. Therefore the use of the SV order is a way of selecting which referent is going to be taken as a basis for further predications. The whole sentence is a commentary on the first statement: anger at the lack of government help. In that respect, topicalized utterances appear as assessments, and are strongly linked to the preceding context.

Those pragmatic values, contrast-emphasis and selection for assessment, can be ascribed to a semantic operation, scanning: the speaker mentally runs through ('scans') a limited set of possible starting points for her/his predication, on the basis of the preceding exchange, and one element of the set is selected at the exclusion of the others. Topicalization, in our data, consists in selecting one of those referents as a thematic goal, to the exclusion of other possible ones. The preverbal position has to 
do with planification of the thematic structure of the exchange, in the sense of Tomlin \& Rhodes (1992:123), who define thematic information as "that knowledge which the speaker assumes is relevant to the goal of the communicative event".

Sometimes, an antitopic appears on the right periphery of the clause. It can be coreferential to the personal affix, or to personal clitics. It is characterized by a clear prosodic break (see Mettouchi 2005b, to appear b) and by the fact that it bears the 'annexation state', which as we will show in 3.3 is a dependency marker.

(12) ye-qqaz tasraft/ye-qqaz ye-qqaz ye-qqaz ye-qqaz

$$
\begin{array}{lll}
3 \mathrm{sm}_{\mathrm{SUBJ}}-\mathrm{dig}_{\mathrm{IMPF}} \quad \text { hole.FS/3 } \mathrm{sm}_{\mathrm{SUBJ}}-\mathrm{dig}_{\mathrm{IMPF}}[\mathrm{x} 4] & \text { sebea yyam/tesraft-nni } \\
\text { armi }=t t & i-f u k k & \text { seven days/hole.AS-ANAPH } \\
\text { until }=3 \mathrm{sf}_{\mathrm{ACC}} & 3 \mathrm{sm}_{\mathrm{SUBJ}}-\text { finish }_{\mathrm{PERF}} &
\end{array}
$$

'He dug a hole, he dug and dug, until he finished it at the end of seven days, the hole.'

These antitopics allow the speaker to complete the basic utterance, either because (s/) he senses that there might be a referential ambiguity, or to emphasize the referent as in (12), because ( $\mathrm{s} /$ )he considers that the co-speaker has not realized its importance for the current exchange. Because antitopics presuppose a relation of aboutness, they belong to the predicate focus structure.

\subsubsection{Argument or verb focus}

As pointed out in 2.1, argument focus, or verb focus, are subsets of the category 'predicate focus': they presuppose a relation of aboutness between a topic and a comment, and they consider one element of the predication (in this case an argument, or the verb itself) as being emphasized and contrasted to other possible referents.

The syntactic structure associated to argument or verb focus is the cleft sentence, which in Taqbaylit is realized by a non-verbal constituent (XP) preceded by a copula if the XP is neither adverbial nor quantificational, and followed by a relative clause introduced by the relator $i$ (or its irrealis counterpart ara), whose status is still debated, and which is diachronically the reduction of an indefinite marker, translatable as 'what', 'that which' (13-15). More information on clefts can be found in Mettouchi (2003a) and (2003b).

(13) $d$ arrum $i \quad n-e \check{c} c \check{a}$

COP bread.FS REL $^{\circ} 1 \mathrm{p}_{\mathrm{SUBJ}}$-eat $_{\mathrm{PERF}}$

'it is bread that we ate'

(14) tlata yergazen $i \quad n$-ezra

three men.AS $\mathrm{REL}^{\circ} 1 \mathrm{p}_{\text {SUBJ }}$-see ${ }_{\text {PERF }}$

'we saw THREE MEN'

(lit. it is three men that we saw) 


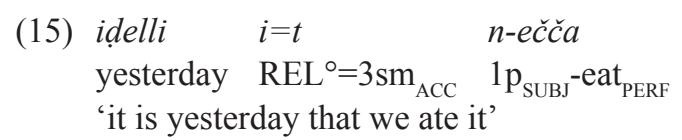

Verb focus is also conveyed by clefts in Taqbaylit; the XP being the verbal noun (here anadi) corresponding to the verb (nadi) in the cleft clause:

(16) $d$ anadi ara nadi-n

COP research.FS REL* search $_{\mathrm{AOR}}-3 \mathrm{pm}_{\mathrm{SUBJ}}$

'they will search all right (lit. it is search that they will search)'

\subsubsection{Sentence focus}

Sentence focus is a sentence construction formally marked as expressing a pragmatically structured proposition in which both the subject and the predicate are in focus.

In Taqbaylit, this type of focus is expressed by the pa-V NP $($ ("VS") configuration. The postverbal NP coreferential to the personal affix is in the annexation state, and is situated either immediately after the verb, or after the object of the verb. In all cases it is prosodically included in the domain of the basic utterance (see Mettouchi 2005, to appear $b$, for more details).

Typically, postposed 'subjects' (in bold) appear in locative-existential contexts, such as for instance the introduction of new referents, which are liable to become topics afterwards, as in the following example:

(17) $l l a-n=d$

ijinyuren/lla- $n=d$

ttbat $/(\ldots) / m a$

$\mathrm{be}_{\mathrm{PERF}}-3 \mathrm{pm}_{\mathrm{SUBJ}}=\mathrm{PROX}$ engineers $/ \mathrm{be}_{\mathrm{PERF}}-3 \mathrm{pm}_{\mathrm{SUBJ}}=\mathrm{PROX}$ doctors $/$ if

d ttbib ur ye-ttaf anda ara i-dawi/ma

COP doctor NEG $3 \mathrm{sm}_{\mathrm{SUBJ}}-$ find $_{\mathrm{IMPF}}$ where REL* SUBJ.3sm-heal ${ }_{\mathrm{AOR}} /$ if

$d$ ajnyur ur ye-ttaf anda ara ye-xdem/ma

$\mathrm{COP}$ engineer NEG $3 \mathrm{sm}_{\mathrm{SUBJ}}-$ find $_{\mathrm{IMPF}}$ where $\mathrm{REL}^{*} 3 \mathrm{sm}_{\mathrm{SUBJ}}-\mathrm{work}_{\mathrm{AOR}} /$ if

d bugatu a nnay ya! xas bbwi-n=d

COP solicitor supplication! even-if take $\mathrm{PERF}-3 \mathrm{pm}_{\mathrm{SUBJ}}=\mathrm{PROX}$

diplomat-nnsen/ma akka $i \quad$ te-qqim

diplomas-POSS.3pm/if so $\mathrm{REL}^{\circ} 3 \mathrm{sf}_{\text {SUBJ }}$-remain $_{\text {PERF }}$

lhala=yagi/ye-lla lxuf

situation=this $/ 3 \mathrm{sm}_{\mathrm{SUBJ}}-\mathrm{be}_{\mathrm{PERF}}$ fear

'there are engineers, there are doctors, (...) As for doctors they don't find where to work, as for engineers they don't find work, as for solicitors, good God! Even with their diplomas, if this situation remains as it is, there is fear...' 
In the previous example, typically, new referents are introduced through an existential verb, ili ('be', 'exist'), in the perfective. In our conversational data, 17 occurrences of postverbal subjects out of 60 (28\%) appeared after this verb. Indeed, a frequent context for postposed 'subjects' is thetic utterances, in the sense of Sasse (1987: 511): "categorical sentences contain a predication base about which some state of affairs is predicated, while thetic sentences are simple nonpredicative assertions of states of affairs". The thetic nature of most of those predications is manifest in the fact that they involve change of state verbs that refer to appearance or coming into existence: $\gamma d l$ 'change', $f f \gamma$ 'go out', $\gamma l y$ 'fall', $k s ̌ m$ 'enter'. The predication refers to the manifestation of a state of affairs, instead of stating something about a topic.

Not all the verbs, however, refer to changes of state or coming into existence. In (18), Speaker B says that despite the problems she encountered in her husband's village when she married, she got used to the situation.

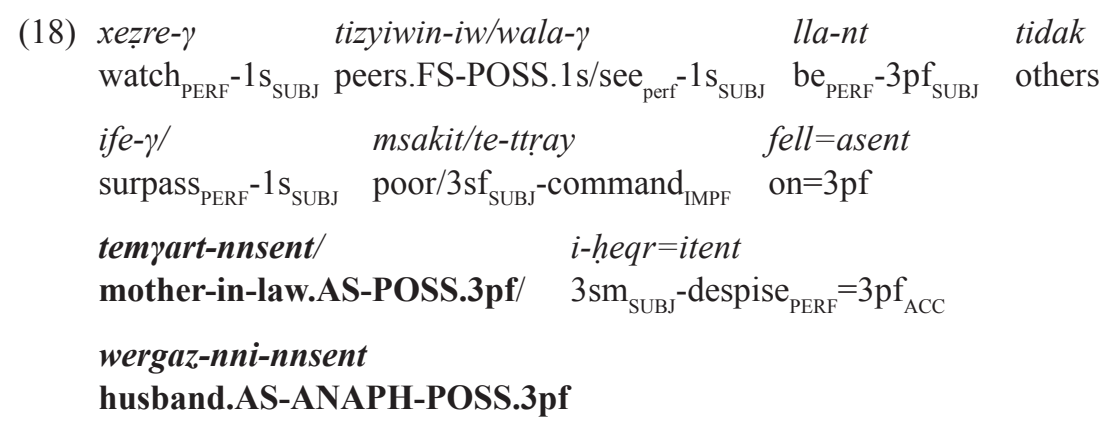

'I looked at my peers (= the other brides), and I saw that there were others that were unhappier than I was, poor girls, their mother-in-law gave them orders, their husband despised them.'

This example shows situations seen as a whole. Mothers-in-law or husbands are not topics (both referents will subside into oblivion immediately afterwards; the real topic here is the other brides (msakit, 'poor girls', indexed by the dative or accusative clitics =asent and =isent)). It is their behaviour as a whole (commanding or spiteful) which is important for the speaker. This behaviour is culturally coded: traditionally, mothers-in-law are perceived as commanding, and husbands as spiteful towards their wives. The possible gloss 'with their commanding mothers-in-law and their spiteful husbands' underlines this close relationship between $\mathrm{V}$ and $\mathrm{S}$.

Finally, VS configurations are found in collocations and expressions, as in example (10), of which the relevant line is reprinted here as (19):

(19) tamyart $\boldsymbol{y}$-uү lhal t-ruh old.woman.FS $3 \mathbf{s m}_{\mathrm{SUBJ}}$-take $_{\text {PERF }}$ situation $3 \mathrm{sf}_{\mathrm{SUBJ}}-\mathrm{go}_{\mathrm{PERF}}$ early '(as for) my mother-in-law, it happened that she died early' 
The expression $y$-u lhal ('it happens that', lit. 'the situation takes') could easily be taken off from the utterance, yielding tamrart t-ruh zik ('my mother-in law died early'). It could never be phrased with a preposed subject *lhal $y$-u .

In the following example, speaker B says that she had no real choice: she had to leave her husband's village because of the situation of her in-laws.

$$
\begin{aligned}
& \text { (20) akken ye-lla wass } a=t \quad y \text {-eks } \\
& \text { so } \quad 3 \mathbf{s m}_{\mathrm{SUBJ}}-\mathrm{be}_{\mathrm{PERF}} \text { day.AS IRR }=3 \mathrm{sm}_{\mathrm{ACC}} \mathbf{3} \mathbf{s m}_{\mathrm{SUBJ}} \text {-take-to-pasture }{ }_{\mathrm{AOR}} \\
& \text { umeksa akken te-lla ddunit } a=t t \quad n \text {-elhu // } \\
& \text { shepherd.AS so } 3 \text { sf }_{\mathrm{SUBJ}}-\mathrm{be}_{\mathrm{PERF}} \text { life } \quad \mathrm{IRR}=3 \mathrm{sf}_{\mathrm{ACC}} 1 \mathrm{p}_{\mathrm{SUBJ}}-\mathrm{walk}_{\mathrm{AOR}} / / \\
& \text { 'We have to adapt to circumstances (lit. according to the day, the shepherd }
\end{aligned}
$$

Here again, the morphological relationship between eks ('take to pasture') and umeksa ('the shepherd') is self-evident (they share the same root KS), and both elements form a unit, with a certain degree of redundancy (the shepherd being generic): pasturing must be done according to the weather, just as life must be conducted according to circumstances. The shepherd is not a topic, and cannot be preposed: *akken ye-lla wass, ameksa $a=t y$-eks.

What characterizes expressions is the close relationship between $\mathrm{V}$ and $\mathrm{S}$, the fact that they form a unit, that their co-occurrence is a higly common collocation based on cultural expectations or world knowledge. They represent the other pragmatic pole of Tomlin \& Rhodes's opposition (thematic vs shared information), namely shared information, defined as "that knowledge which the speaker assumes he has in common (through like experience) with the hearer" (1992:123).

The notion of shared information is all the more relevant as detailed counts on our conversational corpus showed that the SV order never appeared in relative clauses (including clefts), and that conversely, out of $60 \mathrm{VS}$ combinations, 10 (16.6\%) occurred in relative clauses, which are massively presuppositional.

In narratives, typically, postverbal 'subjects' appear in locative-existential contexts, such as for instance the introduction of new protagonists, who by definition are thematically important in the subsequent discourse, as is the case for teqcict, 'girl', in the following example:

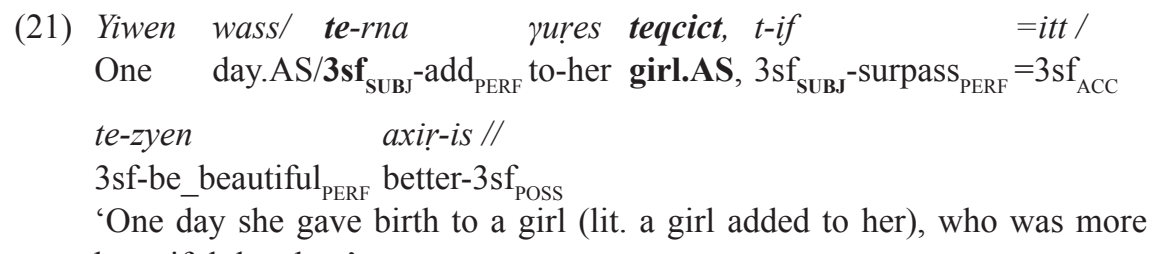
beautiful than her.' 
As mentioned earlier, postposed subjects are particularly frequent in thetic utterances. In our examples, the verb and the postposed 'subject' are treated as a unit, either in an event-type predication (with a possible gloss in ' $\mathrm{X}$ appears/happens...') or in collocations, the semantic load of the pa- $\mathrm{V} \mathrm{NP}$ seing shared between the verb and the NP. In none of the cases is the 'subject' treated as a topic, or more generally, as the starting point of the predication.

Very often, those predications involve so-called 'inaccusative' or 'ergative' verbs.

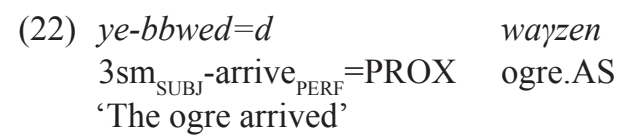

However, these are not the only classes of verbs that trigger the VS word order. The following example is the idiomatic expression of subsiding anger.

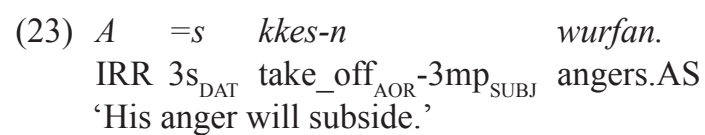

In those expressions, the relationship between the verb and what has traditionally been called 'complément explicatif' or 'expansion référentielle' is very close, the verb being generally rather 'empty' semantically (or at least very frequent and apt to be complemented by a number of possible NPs) and the NP bearing the major semantic load of the utterance.

Predictability does not seem to be an issue: in 'appearance' predications the NP can be considered as unpredictable whereas it is utterly predictable in idiomatic expressions. Theticity seems to be a more central factor for the presence of a postverbal 'subject'. The common feature in all our examples is that the verb and the postverbal 'subject' are treated as a unit, either in an event-type predication (with a possible gloss in ' $\mathrm{X}$ appears/happens...') or in collocations. In none of the cases is the 'subject' treated as a topic.

\subsection{Focus structure and syntactic domains}

To sum up topic/focus articulation in Taqbaylit, we can say that clefting is associated with argument- or verb-focus, whereas NP ordering is associated with:

- sentence focus (pa-V NP ("VS"): postverbal, core-internal position of the NP coreferent to the subject)

- or predicate focus,

$\circ$ either with topic shift or topic anchoring for an assessment $\left(\mathbf{N P}_{\mathbf{S} / \mathbf{A} / \mathbf{D}} \ldots \mathbf{p a}-\mathbf{V}\right.$ ("SV"): pre-head position of an NP), 
or for continuing topic (pa-V(O) : no coreferent NP expressed),

$\circ$ or for antitopic (pa-V(+Clitic) // $\mathbf{N P}_{\mathbf{S} / \mathbf{A} / \mathbf{D}} \ldots$ : the NP coreferent to an affix or clitic is right-dislocated)

These configurations happen to be linked both to position, and to case-marking: whereas in clefting, and for marked topics, the NP is always in the free state (citation form), in sentence-focus and for antitopics the NP is in the annexation state.

In terms of syntactic configuration, all pre-head NPs are in the free state. The situation is more complex for the postverbal NPs: direct objects are in the free state, whereas all NPs co-referential to a personal ${ }^{8}$ affix or clitic must be in the annexation state.

\begin{tabular}{|c|c|c|c|c|c|c|c|}
\hline \multirow{2}{*}{\multicolumn{2}{|c|}{\begin{tabular}{|l} 
Marked topic \\
Pre-core
\end{tabular}}} & \multicolumn{2}{|c|}{ Head (Clitics) } & Affix-Verb & \multicolumn{3}{|c|}{ Object and coreferent NPs } \\
\hline & & \multicolumn{5}{|l|}{ Core } & Postcore \\
\hline \multirow[t]{2}{*}{ a } & arrum & $\mathrm{ad}$ & $=\mathrm{as}=\mathrm{t}=\mathrm{id}$ & y-efk & uqcic & & \\
\hline & bread.FS & IRR & $\mathrm{DAT}=\mathrm{ACC}=\mathrm{PROX}$ & he-give.AOR & boy.AS & & \\
\hline \multicolumn{8}{|c|}{ "the bread, the boy will give it to him" } \\
\hline \multirow[t]{3}{*}{ b } & & $\mathrm{ad}$ & $=\mathrm{as}=\mathrm{id}$ & t-exdem & teqcict & tiqrifin & \\
\hline & & IRR & $\mathrm{DAT}=\mathrm{PROX}$ & $\begin{array}{l}\text { she-make. } \\
\text { AOR }\end{array}$ & girl.AS & crêpes.FS & \\
\hline & \multicolumn{7}{|c|}{ "the girl will make pancakes for her/him" } \\
\hline \multirow[t]{3}{*}{ c } & \multicolumn{2}{|c|}{\begin{tabular}{l|l} 
t-exdem \\
\end{tabular}} & $=\mathrm{as}=\mathrm{id}$ & & tiqrifin & teqcict & \\
\hline & \multicolumn{2}{|c|}{\begin{tabular}{l|l} 
she-make. \\
ACC
\end{tabular}} & $\mathrm{DAT}=\mathrm{PROX}$ & & crêpes.FS & girl.AS & \\
\hline & \multicolumn{7}{|c|}{ "the girl made pancakes for her/him" } \\
\hline \multirow[t]{2}{*}{ d } & & $\mathrm{ad}$ & $=$ tent & t-exdem & tmettutut-is & & $\begin{array}{l}\text { te } \gamma \text { rifin- } \\
n n i\end{array}$ \\
\hline & & IRR & $\mathrm{ACC}$ & she-make & $\begin{array}{l}\text { woman. } \\
\text { AS- } \\
\text { POSS.3s } \\
\end{array}$ & & $\begin{array}{l}\text { crêpes. } \\
\text { AS- } \\
\text { ANAPH }\end{array}$ \\
\hline
\end{tabular}

Table 3: Some configurations in Taqbaylit Berber

This table shows that in Taqbaylit the clause is organized around a head (verb or particle), in the grey column. To the left of the head, in the pre-core slot, we find topic NPs. To its right the situation is not symmetrical: two domains are delimited: the core (particle, pa-V + clitics, $\mathrm{O}$ and postverbal 'subject'), and the postcore (antitopics like teyrifin-nni in (d)). 
The annexation state is neither associated to grammatical function, nor to postverbal position. The only common factor between all its uses at the level of the clause is dependency (as opposed to government) marking. All NPs in the annexation state are to be linked to the core of the preceding basic sentence. This is quite specific to Taqbaylit, other dialects limiting the annexation state to postverbal NPs in the pa-V $\mathrm{NP}_{\mathrm{S}}$ ("VS") configuration (sentence-focus). We have therefore assumed in Mettouchi 2005 that the diachronic path in Taqbaylit was an extension of the annexation-state marking from a semantically motivated case (sentence-focus, thetic utterances) to a syntactically motivated one (coreference with an affix or clitic, associated to the core, or the extension of the boundary of the clause to the right).

\subsection{A diachronic scenario for Taqbaylit}

This section summarizes hypotheses presented in Mettouchi (2005b; 2007, to appear b). We have assumed the sentence-focus/thetic context as being the one that semantically motivated the use of the annexation state. We have linked this context to other ones triggering the same case-marking, namely (a) after all prepositions except for archaic allative ones, (b) after numerals, and (c) in possessive structures, the mark being borne by the possessor.

In Mettouchi (2007, written before 2005b) we proposed a genitive hypothesis for the annexation state, based on Sasse (1984). But in the strict sense of the term, 'genitive' appeared too restrictive, and did not account for the first two contexts above. Moreover, the study of postverbal "subjects" led us to consider that there was an ablative relationship between $\mathrm{NP}_{\mathrm{S}}$ and pa- $\mathrm{V}$ : in the most typical sentencefocus constructions, the notion of detachment from a source prevails (particularly in appearance, or coming-to-existence predicates). It is also to be noted that analytical constructions that have redoubled the annexation state in some contexts (genitives) are based on a preposition $n$ that can be glossed 'of, off'. Numerals operate an extraction on the referent of the NP that follows, and former archaic allative prepositions are still incompatible with the annexation state in Taqbaylit. Therefore, there are elements pointing to a former 'ablative-like' case-marking. We have therefore proposed in Mettouchi (2005b) that in Taqbaylit (or a former form of Berber, or even common Afroasiatic), the two notions 'detachment from a source' and 'aiming at a target' were structuring principles in the grammar of the language. We labelled those two notions 'extended ablative' and 'extended allative'. The extended ablative was what gave rise to the annexation state, the extended allative being the unmarked member of the opposition. This opposition also underlies other domains of the grammar of Taqbaylit.

The diachronic scenario presented in Mettouchi (2005b) involves a first stage in which the annexation state was primarily an ablative marker, with intra-phrasal and intra-clausal uses (the latter with verbs of appearance, coming into existence, etc., then with other types of verbs, as long as the sequence was of the 'sentence-focus' or thetic type). At the level of the clause, the result was that the NPs in the sequence $<$ pa-V NPs $>$ 
came to be considered as a boundary for the core of the clause (which because of its sentence-focus dimension was construed as a single unit). The case mark associated to this boundary was then gradually reinterpreted as underlining the coreference relationship to the personal affix. The relationship between the coreferent NP and the personal (i.e. subject) affix was extended to other coreferential relationships, namely the one between accusative clitics or possessive affixes, and antitopical NPs in the postcore part of the clause. This stage is characteristic of Taqbaylit, and corresponds to the reinterpretation of the annexation state as a dependency marking.

\subsection{Synthesis on Taqbaylit information structure}

We hope to have shown that in Taqbaylit the complex interplay between position and case marking is linked to focus structure, in a way that is specific to this language. The head delimits a prehead domain in which marked ('discontinuative') topics appear, in the free state. The complex $<$ head+verb+affixes and clitics $>$ controls the NPs on its right, with the direct object being in the free state (government), and the coreferential NPs being in the annexation state (dependency). Among those NPs, the $\mathbf{N P}_{\mathbf{s}}$ which is prosodically linked to pa-V belongs to the core of the clause (with the direct object), whereas other right-dislocated $\mathbf{N P}_{\mathbf{S} / \mathbf{A} / \mathbf{D}} \ldots$ (antitopics) are in the postcore slot. Types of foci are linked to syntactic domains, as well as to the presence or absence of coreferential NPs:

- pa-V(O) (unmarked topic) or pa-V(+Clitic) // $\mathbf{N P}_{\mathrm{S} / \mathbf{A} / \mathbf{D}} \ldots$ (antitopic) : continuative predicate focus

- $\quad \mathbf{N P}_{\mathrm{S} / \mathbf{A} / \mathbf{D}} \ldots$ pa-V (marked topic): discontinuative predicate focus

- $\mathbf{p a - V ~ N P}$ : sentence-focus

- Argument or verb focus are of a syntactically different nature, since they involve clefts.

\section{Tashelhit}

Tashelhit, a variety spoken in southern Morocco, appears to be more strictly verb-initial. Varying word orders do occur, but the overall frequency of $\mathrm{VS}(\mathrm{O})$ is considerable.

The first of the following sections contrasts the assumption of a basic $\mathrm{VS}(\mathrm{O})$ word order with a more pragmatically-driven explanation of why word order tends to be more rigid in Tashelhit. On that basis, in 4.2, the syntactic correlates of different focus types in Tashelhit are described. In 4.3, a diachronic scenario of how some of the syntactic slots for core constituents may have come into being will be discussed. This is directly related to morphological case-marking and it will therefore be illustrated how case inflection on nouns depends on their syntactic position in addition to their grammatical relation.

All of these observations are relevant for the comparison of Taqbaylit and Tashelhit 
and the diachronic dimension of discourse-configurationality in Berber that will be addressed in part 5 .

\subsection{Traditional account: Tashelhit as VSO}

The standard description of Tashelhit as basically a VSO language is hardly any different from what has been outlined in section 2 as the broader account of constituent order in Berber at large (cf. Basset 1952, Applegate 1971, Sasse 1984). More recently, Payne in her article on word order variation in verb-initial languages (1995) quotes evidence from Tashelhit gathered by P. Bailey. Although she, too, includes Tashelhit in her typological survey of verb-initial languages, she provides a much more careful syntactic analysis than some of the earlier work. Those who question the applicability of the notion of lexical subject altogether (Galand 1964: 42f.) are very cautious about the concept of a basic word order for Berber syntax. Nonetheless, it is true that $\mathrm{V}$ preceding $\mathrm{S}$ is commonly regarded as more basic or less marked by many.

What motivated the standard view that Tashelhit (as most other Berber lects) is verb-initial? Several pieces of evidence point in that direction. The order of core constituents in thetic utterances is typically $\mathrm{VS}(\mathrm{O})$. The same verb-initial word order is compulsory in subordinate clauses introduced by a conjunction.

$$
\begin{aligned}
& \text { (24) a. } r i-\gamma \quad \text { ad } i \text {-ftu umdakk } l=i n u \quad s \text {-tgmmi } \\
& \text { want }_{\mathrm{PERF}}-1 \mathrm{~s} \text { that } 3 \mathrm{sm}_{\mathrm{SUBJ}}-\mathrm{go}_{\mathrm{AOR}} \text { friend.AS=my to-house.AS } \\
& \text { b. *rir ad amdakkwl=inu i-ftu s-tgmmi } \\
& \text { want }_{\mathrm{PERF}}-1 \mathrm{~s} \text { that friend.FS }=\mathrm{my} 3 \mathrm{sm}_{\mathrm{SUBJ}} \cdot \mathrm{go}_{\mathrm{AOR}} \text { to-house.AS }
\end{aligned}
$$

'I want my friend to go to the house.'

Another, perhaps even more important piece of evidence are text counts of narratives which indicate that the canonical $\mathrm{VS}(\mathrm{O})$ constituent order prevails in terms of overall frequency.

Nevertheless, we have reason to believe that such an account does not do justice to the facts in Tashelhit. While thetic sentences may typically occur with VSO word order, one may actually ask how common such utterances are in everyday spoken language when pragmatic requirements favour utterances with an internal topic-comment (theme-rheme) structure and thus a certain degree of "uneven" focus distribution. As for subordinate clauses, it is true that the major constituents follow conjunctions in VSO order, but this is, of course, not true of relative clauses and sentences with interrogative pronouns, in which constituents are extracted. Wh-question words, e.g., have to be fronted. This is true even in echo-questions, which would appear to be the most likely context in which - if it was possible at all-in situ use of wh-question words would be expected. Concerning the narratives, it is true that text counts show an overwhelming number of VSO ordered sentences. One possible reason is given in Longacre (1982; cf. his earlier quote) and Payne (1995). They describe certain discourse functions of predications with a post-verbal subject that are rather frequent 
in narratives. We will come back to this point after having had a closer look at a Tashelhit narrative.

The analysis of a Tashelhit text (in this case a narrative gathered by Stumme and published as text 2 in an edition of Tazerwalt folktales, Stroomer 2002) gives a better idea of the significance of word order variation with regard to information and text structure. Out of 160 predications (with a third person subject) only 53 have a lexical subject. Of these, 47 have a lexical subject NP immediately following the verb, but no object. Of the remaining ones, five are VSO with both subject and object represented as full lexical NPs. One case has a lexical NP representing a subject that introduces a new character at the right boundary of the clause. It does not follow the verb immediately, but rather a pronominal locative argument:

$$
\begin{aligned}
& \text { (25) } t \text {-ašk }=i d \quad s \text {-dar-sn tfqqirt } \\
& 3 \mathrm{sf}_{\text {SUBJ }} \text {.come }=\text { PROX to-at-theirs old_woman.AS } \\
& \text { '(...) came to them an old woman' }
\end{aligned}
$$

As for direct objects, there are 51 instances in which that grammatical relation is expressed by a full lexical NP. None of these occur in pre-verbal position.

At first sight, these observations seem to corroborate that Tashelhit is fairly strictly $\mathrm{VS}(\mathrm{O})$. There are, at least, two objections to this claim: (a) $\mathrm{VS}(\mathrm{O})$ may be a very frequent word order, but it does not have to follow automatically that other constituent orders need to be analysed as derived from an allegedly basic VS(O) order; (b) even though $\mathrm{VS}(\mathrm{O})$ may be common in terms of its overall number of occurrences, that does not necessarily imply that it is the most widely usable order across different pragmatically characterised communicative events.

While the first observation touches a more theoretical question, the second possible objection is more directly an empirical issue. The following paragraphs illustrate Tashelhit examples in which a constituent order other than $\operatorname{VS}(\mathrm{O})$ containing full lexical core constituents occur.

The examples are taken from another narrative collected by Stumme (included as text 8 in Stroomer 2002). Counting different types of constituent order, the picture looks fairly similar to the previous text, although there are some differences. Lexical nouns are even less frequent. While almost one third of all verbal predicates in text 2 contains a lexical subject, this number goes down to only about one fifth in text 8 . At the same time there is more variation in terms of constituent order (although $\operatorname{VS}(\mathrm{O})$ still prevails!). It may be interesting to note that, while both texts are described as "not very colourful" and rather boring in style by native speakers, the second one fares slightly better than the first in the rather impressionistic native speaker assessment.

We suspect that one reason for this perception may have to do with the technical conditions under which the texts were recorded. They were dictated to Stumme, which may have severely affected their naturalness in terms of pragmatics. It is likely that the texts took on a more report-like character in which pragmatic richness is neglected in favour of a less artful style of moving the storyline ahead while presenting the 
narratives as a mere relation of subsequent events. The latter appears to be a widely attested function of VSO structures, especially in verb-initial languages that tend towards greater word order flexibility (cf. Payne, etc.) ${ }^{9}$.

Be this as it may, there are examples of left-shifted subjects in text 8 , and these show that in specific contexts pragmatic constraints appear to be strong enough to warrant word order variation and pre-verbal core constituents despite the prevalence of VSO in Tashelhit (irrespective of whether the latter is due to a genuine tendency of that language, or specific to the narrative style used in the texts, or simply an effect of the manner in which the data were recorded). The following paragraphs describe environments where pre-verbal subjects are attested.

(a) Episode-boundaries marked by fronted subjects (= external topics):

\{ couple had a daughter who was an ogress and killed their sheep. They did not know about it and blamed their shepherd for not looking after the sheep more carefully. After a brief paragraph on how some sheep are lost every night, and how the couple blames the shepherd, the attention is shifted to the ogress-girl:\}

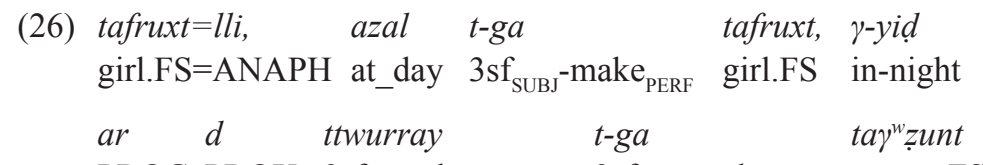

PROG PROX $3 \mathrm{sf}_{\mathrm{SUBJ}}$.change $\mathrm{IMPF}_{\mathrm{IMP}} 3 \mathrm{sf}_{\mathrm{SUB}}-$ make $_{\mathrm{PERF}}$ ogress.FS

'That girl, during the day she was a girl, at night she changed and became an ogress.'

In that function, the topicalized subject is typically followed by anaphoric lli. There is good reason to assume that the construction is an external topicalization: additional material can easily be inserted between the (external) topic and the VP (cf. azal 'during the day' in the preceding example).

(b) Another observation concerns the relatively high frequency of structures with a fronted subject in which the verb is iga 's/he is'. The following post-verbal complement is a predicate noun rather than a direct object, which is due to the fact there has been a semantic shift of the verb eg from 'make' to 'be' in Tashelhit.
(27)

$\begin{array}{llll}\text { Abadan, xtann } & \text { ur } t \text {-gi } & \text { ta }^{w} \text { zunt! } \\ \text { no } & \text { that_one } \mathrm{NEG} 3 \mathrm{sf}_{\text {SUBJ }} \text {-make } & \text { NEG.PERF } & \text { ogress.FS } \\ \text { 'Absolutely not; that one is not an ogress!' } & \end{array}$

(c) It should also be noted that left-shifted core constituents occur in particular in dialogue portions of the narratives. Out of altogether six examples with pre-verbal subjects, four occur in direct speech (the other occurrences are found in first sentences marking a new episode, as outlined above).

On the basis of these observations, we can summarise that, in comparison to 
Taqbaylit, the total number of pre-verbal lexical core constituents is smaller, but they still do occur. It thus appears that Tashelhit may be less flexible than Taqbaylit with regard to constituent order, but it is still far from being rigidly verb-initial. The prevalence of $\mathrm{VS}(\mathrm{O})$ order in clauses with lexical NPs is likely to be due to genreeffects, recording and processing.

Spoken language does not convey a similar impression as the text counts. In fact, it has just been noted that clauses with pre-verbal lexical core constituents occur typically in direct speech sections of the narratives. Since we lack spoken language corpora for Tashelhit, we had to rely on elicitation to supplement our data and gain a more insightful description of focus and the factors relevant for distinct word orders. The Tashelhit informants are male, in their 30s and speak Arabic and French, as well as Catalonian, Spanish and/or German as further languages. ${ }^{10}$

\subsection{Focus and topicality in spoken discourse}

In order to elicit sentences containing word order contrasts, we created a number of possible contexts which would seem likely to trigger utterances representing different focus types. Often these were plain question-answer pairs, but in some cases the replies that informants were meant to create were rather reactions in which they would contradict the triggering statement. In order to be clear about the pragmatic characteristics of the respective statements, we usually provided a relatively broad description of the situation in which the respective trigger utterances were embedded. In addition to the positive evidence given by informants, we cross-checked whether alternative orderings of constituents seemed acceptable to them in the respective contexts. If so, we tried to uncover possible semantic and pragmatic differences of any permissible alternatives. These direct contrasts between minimally distinct utterances, and those cases in which alternative word orders were rejected by informants, helped us to discover the cues triggering specific word orders and to delimit their respective functional ranges. The following is a brief description of how the major focus types are expressed in Tashelhit.

\subsubsection{Thetic statements}

What is characteristic of thetic statements is that they lack any inherent structuring into two different parts in terms of information value. They do not contain a sequence of a clearly discernible topic (theme) about which a comment is made (rheme). In pragmatic terms, they contain all new information. They have, therefore, also been characterised as out-of-the-blue statements that are entirely in focus, corresponding to Lambrecht's sentence focus articulation type. In Tashelhit, as an answer to a broad question such as 'what is going on there?', we were given the following examples: 
(28) a. isbaqqi (yan) ufrux butsuf

$3 \mathrm{sm}_{\text {SUBJ }}$ - punch $_{\text {PERF }}$ one boy.AS balloon

'a boy ( one boy) has punched a balloon'

b. yan ufrux isbaqqi butsuf

one boy $3 \mathrm{sm}_{\mathrm{SUBJ}}$ - punch $_{\mathrm{PERF}}$ balloon

( $\sim$ 'there is a boy, and he has punched a balloon')

'one boy has punched a balloon'

The VSO word order in (28a) is usually considered the basic word order and corresponds to the expected case. It must be noted, however, that $(28 \mathrm{~b})$ is not ruled out. Its occurrence in this context is more restricted in that it needs to be accompanied by the numeral yan/yat 'one (m./f.)', possibly indicative of an initial phase of grammaticalisation of that numeral into an indefinite article. The combination of the numeral yan with a noun as in (28b) could be analysed as a non-verbal presentative construction followed by a juxtaposed verbal predicate. Such a construction could have a similar functional motivation as the French sentence focus construction exemplified by (il) y a le téléphone qui sonne 'the phone is ringing ( $<$ there is the phone that rings)'. In French, the sequencing 'topic-comment' is an important organising principle; at the same time, constituent order is fairly strictly SVO. Since simple word order change is rather restricted, the expression of non-topic subjects requires a rather complex structure (cf. Lambrecht \& Polinsky 1998). It would be interesting to find out whether this type of pre-verbal subject construction in Tashelhit is influenced by contact with French. An important piece of evidence might come from monolingual speakers of Tashelhit. The contact hypothesis would gain support if they used this construction substantially less frequently than bilinguals, if at all. Unfortunately, for the time being we can only suggest this as a hypothesis, but do not have the data from monolinguals relevant for the issue. It might be interesting to note, however, that Taqbaylit appears not to use sentences of the type illustrated in (28b) under similar pragmatic conditions.

\subsubsection{Predicate focus}

Predicate focus articulation is found in utterances which distinguish a topic about which a statement is made. The topic (or theme) is often (cf. 29a), but not necessarily (29b), the NP corresponding to the subject.

(29) a. [dialogue between mother and son; son is trying on shoes; mother asking: mma xtid? 'What about these?']
(xtid) ar=yyi tqqssnt
these $\quad \mathrm{PROG}=\mathrm{me} \quad \operatorname{hurt}_{\mathrm{IMPF}} .3 \mathrm{pf}_{\mathrm{SUBJ}}$
'these hurt me' 
b. [after an accident that occurred the previous day, a person enquires: manika-nn iga ukrum-nnek? 'How is your back now?' ]

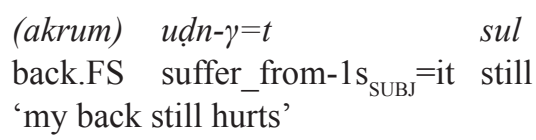

The full lexical NPs referring to the subject in (29a) and the direct object in (29b) are fronted. This position is typically referred to in Berber studies as the slot for topicalised constituents. In addition to their topicality, they carry a certain amount of extra emphasis. It has to be noted that the literal repetition of the constituents xtid and akrum is optional. The answers would be felicitous if they did not contain these elements (hence the brackets). In fact, a plain informative answer to the questions in (29a) and (b) would rather not contain explicit lexical topics (except, of course, for the respective subject markers and/or object clitics on the verb). If the topics are made explicit, they are usually understood to contrast with some other implicit entity. Accordingly in (29b), the person's back would then be understood not to have been the only body part that was injured during the accident. Similarly in (29a), the explicit mention of xtid lays more emphasis on the fact that the pair of shoes referred to is one among others that the boy has tried on. It should be noted, however, that these are cases of contrasted topics; strict contrastive focus is expressed differently; see below. The difference between thetic statements and predicate focus is perhaps most obvious with regard to independent pronouns functioning as core constituents. It must be remembered that minimal sentences do not require the use of independent pronouns. Therefore, the use of an absolute pronoun always indicates that there is some kind of emphasis on the respective constituent.

Similar to contrastive lexical constituents, absolute pronouns co-referential with the subject marker on the verb express contrastive emphasis if they occur clauseinitially, cf (30):

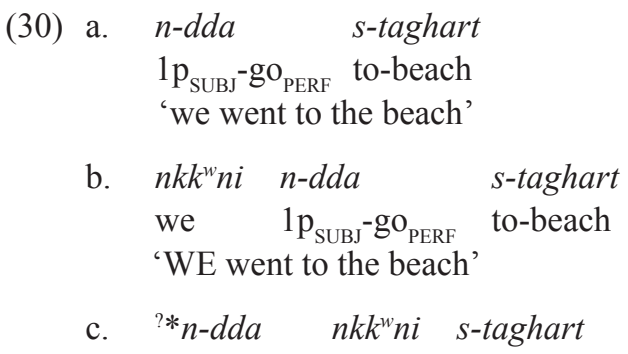

In contrast to lexical NPs, absolute pronouns do not actually add any semantic information to the one co-encoded by the subject marker itself. ${ }^{11}$ Therefore, there is no real need for them to be used in the unstressed position, i.e. immediately following the verb. While a post-verbal lexical NP co-referential with the subject marker is relatively common (cf. the text counts in 4.2), there is no pragmatic motivation for 
absolute pronouns to occupy that position; hence the oddity of (30c).

\title{
4.2.3 Verb focus
}

The notion of verb focus poses a problem in a language where no explicit mention of core constituents other than the cross-reference on the verb is needed to form a felicitous sentence. If the verb, and just the verb, is in focus, the other core constituents are not likely to be represented by full lexical items. One will simply get the respective markers on the verb itself.

Trying to elicit utterances that would single out the verb and place special emphasis on it, we have not been able to discern a specific construction used in Tashelhit for the expression of contrastive (he's READING [not writing!]) or newinformation (READING is what he's doing) focus on the verb. The most natural way of expressing a notion of contrast on the verb was to negate a prior statement and make an affirmative assertion which consists of the respective verb only ([he] isn't writing, he's reading.).

A nominalised verb form can occur as a sentence-initial external topic, followed by a sentence containing the same root as an inflected verb. This construction is used to lay special emphasis on the verb (e.g. in order to contradict a prior statement or to stress that something has been done properly). English equivalents that paraphrase this function are '(as for) reading, he read' or 'read, he did'. It is not, however, a cleft construction presenting the verb as new information as can be seen by the fact that it cannot be used as an answer to a question such as 'what did he do with the books?'.

\subsubsection{Argument focus}

By argument focus we understand a type of emphasis that singles out one particular constituent and contrasts it with conceivable alternatives. The corresponding construction assigns new information status to the focussed constituent, combined with a notion of counterexpectation. Argument focus is expressed by a cleft construction. Depending on what constituent is "extracted", the subordinator is formally different. Example (31a) to (c) illustrate clefting of a subject, a direct object and an indirect object.

\author{
(31) a. A: manwa irgln taggurt? \\ who lock.PERF.PRTCP.s door.FS \\ 'who locked the door?' \\ B: $n k k^{w} n i \quad a(d) \quad=s t t$ irgln \\ we REL =it lock.PERF.PRTCP.s \\ 'WE closed it; it was US who closed it' \\ \{NB: verb in participial form in subject clefts!\}
}


b. [sth. seems to bother B. A knows that B's knee is often causing problems:]
A: is tudint
afud?

INTERROG suffer_from. $2 \mathrm{~s}_{\text {SUBJ }}$ knee.FS

'Is your knee hurting?'

B: (uhu,) aḍar ad $u d \underline{n-\gamma}$

(no,) foot.FS REL suffer_from- $1 \mathrm{~s}_{\text {SUBJ }}$

'(no,) my FOOT hurts; it is my FOOT that hurts'

c. A: mamu tkfit aghrum?

whom give PERF $^{2} 2 \mathrm{~s}_{\text {SUBJ }}$ bread.FS

'whom did you give the bread?'

B: nettat a mu kfi-x aghrum

she SUPPPRON to_whom give PERF $-1 \mathrm{~s}_{\text {SUBJ }}$ bread.FS

'HER I gave the bread; it is to HER that I gave the bread'

The cleft construction needs to be distinguished from the mechanism of subject fronting. Fronted subjects immediately precede the verb. They are marked for free state (sometimes also referred to as absolute case), and thus differ formally from post-verbal subjects. Fronted subjects are highly topical and usually carry contrastive emphasis. The following example with full lexical NPs illustrates how notions of topicality and contrastive emphasis intersect.

(32) \{mad syant Zinb d-Yamna

\section{na?} kra

'what did Zinb and Yamna buy?'\}

Zinb $t$-s $\gamma a$ $n-l x^{w} d e r t$,

Yamna

Zinb 3 sf $_{\text {SUBJ-buy }}$ PERF $_{\text {a_little of-vegetables Yamna }}$

t-sja azalim.

3 sf $_{\text {SUBJ }}$-buy ${ }_{\text {PERF }}$ onion

'Zinb bought some vegetables, and Yamna bought onions.'

Fronted subjects differ in case marking from the corresponding post-verbal subjects:
(33) a. $t-k \check{s} m$
tfruxt tigmmi
3 sf $_{\text {SUBJ-enter }}$ girl.AS FS.house
'the girl entered the house'
b. tafruxt t-kšm tigmmi
girl.FS $3 \mathrm{sf}_{\mathrm{SUBJ}}$-enter FS.house
'the girl entered the house'

Clause-internal fronting is also different from clause-external topicalisation. Core constituents can occur in sentence-initial, but clearly clause-external position. Prosody serves to distinguish between external topicalisation (with a clear intonation 
break between the topic and the following phrase) and plain fronting if the subject is the only pre-verbal constituent. This type of left-dislocation can co-occur with plain fronting as illustrated in the following example. Note that the left-dislocation of nonsubject constituents makes the use of clitics in the core clause obligatory.

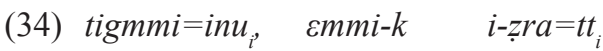
house.FS=my, uncle-your $3 \mathrm{sm}_{\mathrm{SUBJ}^{-}}$-see $_{\mathrm{PERF}}=$ it 'my house, your uncle's seen it'

The occurrence of two pre-verbal core constituents (OSV or SOV sequences) could be analysed as a sequence of an externally topicalised core constituent followed by a second, fronted core constituent. We favour an analysis in terms of a pragmatically highly-marked double-topic construction for various reasons: this type of construction is extremely rare; there is always a prosodic rupture between the object and the following VP; and object clitics are compulsory in these constructions. All of this points at an external rather than a fronted, but internal, status of the lexical object NP.

(35) presents a clefted object (a) and a preposed object (b). The situation that was given in the elicitation was the same for both answers. Person B had both his back and the shoulders injured in an accident. Person A inquires about B's health some time after the accident.

(35) \{A: manika-nn tga tyrut d-ukrum-nnek?

'How are your back and your shoulder?'\}

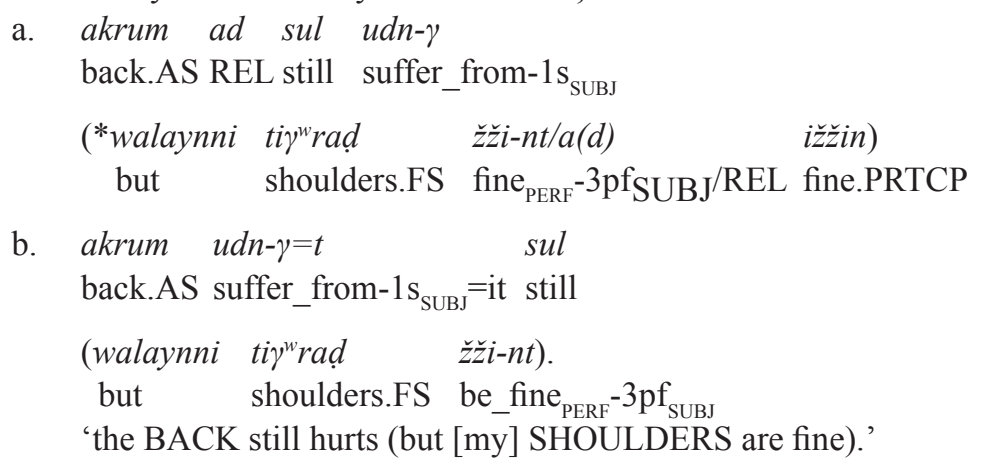

There is a noteworthy semantic difference between the two examples. The intended meaning of the reply is the same for both, although it must be noted that the addition of an explicit statement 'but the shoulders are ok' is pragmatically odd in combination with the cleft construction in (a), because it simply reiterates information that is already implicit in the first part of the sentence. Interestingly this notion of strictly selecting between two mutually exclusive alternatives is felicitous, although the question does not imply in any way that only one of the two injured body parts could still be causing problems. 
In contrast, in (b) the second part of the sentence given in brackets is fully acceptable and adds new semantic information. In this sentence, akrum is simply singled out as a topic about which a statement is made. This implies some notion of contrastive focus, but not to the same extent as in the cleft construction. Accordingly, the addition of the optional part mentioned in brackets is possible (as would be a continuation of the statement with "and also my shoulders still hurt, but less than my back/less than before").

4.3 The emergence of word order patterns and differences in case-marking in Tashelhit

As the preceding section on different focus types has shown, there is a rather broad array of syntactic mechanisms serving to comply with pragmatic requirements calling for the expression of focus. On formal grounds, the most easily distinguishable such mechanism is the cleft construction with $a(d)$. Moreover, there is plain fronting of constituents and the possibility of having a constituent in an external topic slot preceding the clause. All of these strategies pose certain challenges for synchronic and diachronic analysis. Two of these will be discussed briefly here: the status of the $a(d)$, and the variation in case-marking according to pre- versus post-verbal position in connection with the diachrony of plain fronting.

\subsubsection{The status of $a(d)$}

As for the argument focus construction with $a(d)$, the analysis we propose is very similar to that given in Mettouchi (2003b) for a similar construction in Taqbaylit. Originally, we are dealing with a cleft construction. The focussed constituent precedes the relative clause. The focussed constituent is immediately followed by $a(d)$ which introduces the relative clause. The status of $a(d)$ is not fully clear. Diachronically there is little doubt that it served as a relativiser introducing the core clause from which the focussed constituent was "extracted". The focussed constituent itself probably used to be preceded by the copula $d$. The use of the cognate copula $d$ is still compulsory in the corresponding construction in Taqbaylit. In Tashelhit, this is not the case in affirmative statements, but the copula is still used in negative utterances.

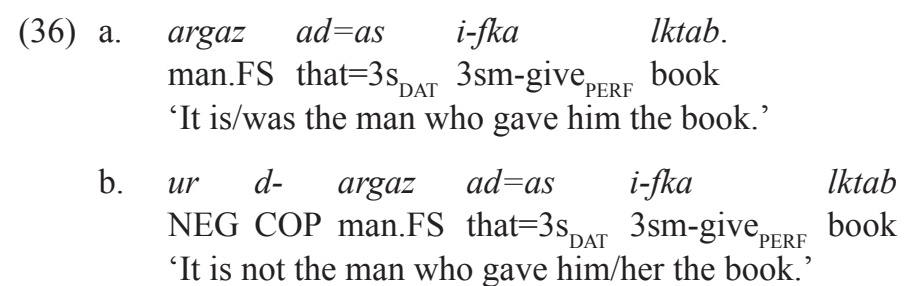

The affirmative construction may convey the impression that $a(d)$ is developing into a focus marker. There is, however, no prosodic or syntactic evidence for such an 
analysis. It must be noted that clitic elements in the relative clause attach to $a(d)$ indicating that this element still functions as a relativiser and is part of the relative clause. For Tashelhit, this structure is therefore best interpreted as a cleft construction which is formally reduced in the sense that it does not require a copula.

\subsubsection{Case-marking difference between pre- and post-verbal subjects}

A similar process has been argued to be responsible for the case marking distinction between lexical subjects in pre-verbal position and those occurring immediately after the verb (cf. the contrast in (33a) and (b)). In an article on case-marking in Cushitic, Semitic and Berber, Sasse (1984) provides an explanation for the contrast in case-marking between pre- and post-verbal subjects. Subjects that follow the verb immediately as in VSO structures used for thetic statements are marked as état d'annexation (corresponding to Sasse's subject case and marked nominative in the terminology used by König 2006). If the subject precedes the verb, it shows absolute case-marking, i.e. it occurs in the état libre, which is the unmarked case used for direct objects in transitive clauses, predicate nouns and as a citation form for nouns in isolation.

What would have to be assumed to account for the absolute/independent state marking for pre-verbal subjects is that they were once outside the clause and received their case-marking not by the verb of the core clause. Sasse points out that this may happen if the focussed constituent is presented as a predicate noun in a copula construction preceding a relative clause in Cushitic (1984: 113) and certain constructions in Arabic (119f.). This corresponds closely to what we have seen in the previous paragraph. In functional terms, however, this appears to be problematic. While the assumption of a former cleft construction accounts nicely for the contrast in case-marking, the left-shifted subject would have to be assumed to be focalised rather than topicalised (as is the case in the construction outlined above). In the case in question, plain fronting of subjects (or any other core constituent, for that matter) is a topicalisation mechanism. It does not seem unlikely that there has been a clauseexternal position at the left boundary of the sentence for a rather long time which could be occupied by almost any constituent. This constituent would always be unmarked for case (and thus carry the default, i.e. absolute/accusative case marker). At some stage, there must have been a reanalysis of pre-clausal subject nouns. They were reinterpreted as not being external to the clause, thus allowing for another element to occupy the external topic position, even if there was a subject noun preceding the verb. A word order pattern with an absolute-marked, clause-internal subject noun immediately preceding the verb can have developed along these lines.

These explanations, however, do not fully clarify the intricacies of case-marking in the languages in question. The assumption of cleft constructions and (diachronically fairly stable) external topic positions accounts for the formal difference in case-marking of pre- versus (immediate) post-verbal subjects. Unfortunately, there remain a number of unsolved problems. One of these concerns the question of why nouns following 
a preposition or numeral take the same case marking as a post-verbal subject? A possible answer will have to take into account the reorganisation of the noun inflection in the course of Berber language history leading to some otherwise perhaps rather unexpected mergers of different functions into one formal marker (cf. the discussion of allative and ablative functions at the core of the Berber case distinction in 3.4). This has brought about a situation in which what may originally have been a more prototypical morphological case-marking system mapping semantic relations onto syntactic functions was altered substantially. Hence the somewhat unusual "case" terminology of free versus annexed state in the francophone tradition of Berber studies. Taqbaylit took these changes further than Tashelhit and shows dependent case (= postverbal subject) marking, i.e. annexation state, on right-dislocated direct objects. In this regard, Tashelhit is closer to a more prototypical case-marking system in that the noun inflections under question conform to the mapping of semantic relation onto syntactic function in a fairly straightforward way as long as the respective constituents are post-verbal.

\section{Word order flexibility and discourse-configurationality over time}

The main points of the two preceding sections can be subsumed under three major topics. By contrasting Taqbaylit and Tashelhit, the following observations can be made.

(1) Berber lects show a considerable variation with regard to issues concerning information structure, focus articulation and discourse-configurationality. While there is good reason to classify Taqbaylit as discourse-configurational, Tashelhit is somewhat more restrictive in terms of word order flexibility.

(2) Matters of case-marking are directly related to this. The functions of the declensional morphology on the noun have shifted considerably in Taqbaylit. The distinction between free state and annexation state is more clearly a dependencyoriented phenomenon in that language, while it corresponds more closely to a subject (or marked nominative) versus absolute case system in Tashelhit (although there are tendencies of a similar kind as those observed in Taqbaylit: after all, genitive functions are taken over by the subject case, showing that a dependencynotion rather than the mapping of semantic relations onto syntactic functions is at the core of noun declension).

(3) Despite a considerable degree of word order flexibility, there has not been a generalised shift from VSO to SVO.

What are the diachronic implications of these observations? Apparently, at different stages in the history of the Berber language group, strategies that presented core constituents in pre-verbal position have grammaticalised into various pragmatically significant constructions. 
Clause-external topicalisation is one of these strategies. It is widespread and has (probably for a rather long time) been a generally available strategy in Berber for bringing core constituents into pre-verbal position. This type of topicalisation is often marked prosodically, but phonological phrasing can change over time and phrasal boundaries be reinterpreted, so that external topicalisation is a possible point of departure in the development towards plain, monoclausal variant word order types.

Cleft constructions typically serve to express argument focus and contrastive emphasis. In the languages under study, the segmental make-up of these constructions has been more and more reduced. At some stage, the erstwhile cleft construction was reinterpreted as monoclausal, with a focus marker going back to a relativiser or support pronoun (Mettouchi 2003 b). For Tashelhit, the biclausal nature of the construction is still clear, if we are to rely on intonation patterns, which form two distinct intonation units; on the other hand, the copula has disappeared in positive sentences, but this does not lead to potential confusion with plain relative clauses as the relator is different ( $n n a, l l i$ versus $a d$ ), nor with independent or main clauses, because of the presence of this relator. In Taqbaylit, intonation points at a monoclausal construction, and the copula is still indispensable for argumental focus (as opposed to adverbial focus). The relator is the same as for relative clauses, but the presence of a copula for nominals precludes any confusion with plain relative clauses. It seems therefore that even when the material undergoes diachronic changes that might lead to an alignment between topics in main clauses and foci in clefts, morphosyntactic marking prevents this confusion from happening.

In some Tamashek varieties, the focus marker tends to be omitted (Heath 2005: 643). This leads, again, to a clause type with what looks like a plain word order variation, showing one core constituent in pre-verbal position. It is important to note that such a construction fulfils a completely different function than others outlined in the previous paragraph.

As a result of this, the pre-verbal position can be understood to be fairly contested as a possible endpoint of the grammaticalisation paths described above. A typical development in the course of language history would be to have a subject that corresponds to the topic, and with a topicalisation mechanism involving fronting, a frequent pattern might be for the subject to occur in pre-verbal position. Eventually, this might bring about a more generalised syntactic pattern of SVO.

There is little evidence that this is taking place in the two lects under scrutiny. As far as Taqbaylit is concerned, the very strong argumental nature of personal affixes is certainly a feature going against any SVO shift, the pre-head slot being functionally rather than syntactically motivated. A shift to SVO should be facilitated by the shift from pronominal argument to plain agreement, and therefore to full subjecthood of the NPs. Despite significant differences with regard to the syntactic "weight" of personal affixes and pronominal clitics, the situation looks similar for Tashelhit. Topicalised NPs coreferential with the subject occur to the left of the verb, but they are not frequent, given the fact that continued topics are not expressed by lexical NPs (nor pronouns). As pragmatic pivots in contrast to other core constituents, they seem not 
to be sufficiently salient in pre-verbal position so as to spark off a more generalised syntactic change to canonical SVO.

As for the postverbal position, it has different synchronic values depending on the lects. For the two lects under study, we can hypothesize a common development until stage 3, when the languages took different paths:

Stage 1: use of the extended ablative to mark semantically-motivated patterns (coming into existence, appearance, coming out etc.),

Stage 2: extension of the case mark to sentence-focus,

Stage 3: in Tashelhit apparently the case mark remained limited to subject-marking, thus giving rise to a marked nominative vs absolute type of language,

Stage 3: in Taqbaylit the case mark kept on its relational value, but instead of a strict Verb-Subject relationship, it extended to the Affix/Clitic-Dependent NP relationship.

Despite the different developments at stage 3, both varieties are similar with regard to the diachrony of word order variation. Rather than a generalised shift from VSO to SVO, we find a number of grammaticalised word order patterns. Each of these "competing" sentence types serves specific pragmatic functions. Shared typological characteristics (optionality of lexical nouns/pronouns corresponding to core constituents, a former active-stative system implying a relatively high number of unaccusative verbs, low degree of subjecthood, i.e. weak tendency to link a pragmatic pivot to a syntactic subject function) bring about an interesting situation: Instead of a VSO $>$ SVO shift, pragmatics trigger the emergence of (relatively stable) discourse-configurationality.

\section{Abbreviations}

$\begin{array}{llll}1,2 \text { or } 3 & \text { refer to person } & \text { CAUS } & \text { causative prefix } \\ \mathrm{S} & \text { singular } & \mathrm{CL}_{\mathrm{ACC}} & \text { accusative clitic } \\ \mathrm{P} & \text { plural } & \mathrm{CONC} & \text { concomitance particle } \\ \mathrm{F} & \text { feminine } & \mathrm{COP} & \text { copula } \\ \mathrm{M} & \text { masculine } & \text { DAT } & \text { dative clitic } \\ - & \text { affix boundary } & \text { FS } & \text { free state [if a nominal } \\ = & \text { clitic boundary } & & \text { doesn't mark } \\ \text { ACC } & \text { accusative clitic } & & \text { this opposition, } \\ \text { ANAPH } & \text { anaphoric particle } & & \text { we do not indicate } \\ \text { AOR } & \text { aorist } & & \text { case] } \\ \text { AS } & \text { annexation state (=état } & \text { IMPF } & \text { imperfective } \\ & \text { d'annexion, dependent } & \text { IRR } & \text { irrealis particle } \\ & \text { state) } & \text { NEG } & \text { preverbal negator }\end{array}$




\begin{tabular}{|c|c|c|c|}
\hline \multirow[t]{2}{*}{$\mathrm{NP}_{\mathrm{A}}$} & $\begin{array}{l}\text { nominal phrase } \\
\text { coreferent to the }\end{array}$ & PA-V & $\begin{array}{l}\text { personal affix-verb } \\
\text { (=basic utterance) }\end{array}$ \\
\hline & accusative clitic & PERF & perfect/-ive aspect \\
\hline \multirow[t]{3}{*}{$\mathrm{NP}_{\mathrm{D}}$} & nominal phrase & PROG & progessive particle \\
\hline & coreferent to the & POSS & possessive affix \\
\hline & dative clitic & POSTNEG & postverbal negator \\
\hline \multirow[t]{3}{*}{$\mathrm{NP}_{\mathrm{S}}$} & nominal phrase & PROX & proximal particle \\
\hline & coreferent to the & REL* & irrealis relative marker \\
\hline & personal affix & $\mathrm{REL}^{\circ}$ & realis relative marker \\
\hline $\mathrm{O}$ & lexical direct object & SUBJ & subject affix \\
\hline IPRTCP & participle & SUPPRON & support pronoun \\
\hline PASS & passive prefix & & \\
\hline
\end{tabular}

\section{Notes}

1. We wish to express our gratitude to the organisers of the conference and the editors. We are also indebted to the anonymous reviewers whose comments proved very helpful.

2. Our warm thanks go to the speakers that have accepted to be recorded over the years in their everyday interactions, and to those, family and friends, who facilitated our stays in the village. Special thanks are due to Zouina Mettouchi, Zahra Mettouchi and Tounsia Rabia for their regular participation in our recording sessions.

3. For more details on the (very frequent) proximal particle and its range of values, see Mettouchi 1997.

4. A slash marks a minor intonational boundary, a double slash indicates a major one.

5. 'As soon as the ogre arrived, he told the cat "mmm, Cat, it stinks in here, beware I should have to go upstairs!". The cat replied "some pedlar came by, I bought a comb and a mirror", the ogre said "he is close by, I will catch him and eat him!", the cat replied "it's only this morning that he came by". The ogre started to eat his supper, and told the cat "o Cat, how good today's supper is!"”.

6. Direct objects, however, when they are neither topics nor antitopics, follow the verb directly, without a coreferential accusative clitic.

7. We have only considered verbs completed by 3rd person affixes, and their coreferential S and $\mathrm{O}$, in the form of NPs and independent pronouns.

8. And also possessive affixes.

9. Note, however, that this function is by no means restricted to verb-initial languages. German with its V2 order has post-verbal subjects in narratives, filling the pre-verbal slot either with a dummy $d a$, dann 'there, then', or not filling it at all (actually violating the "strict" V2 structure). Also in French, a language with a fairly strict SVO order allows subject inversion in similar instances, cf. arrivèrent alors les soldats du roi, qui... '[then] came the soldiers of the king, who...'.

10. We are indebted to a number of speakers who patiently helped us with the elicitation and the processing of other data. Two of them, Hassan Akioud and Rachid Ziam, dedicated much 
time and deserve special mention.

11. This is what makes Galand's notion of the post-verbal subject as a complément explicatif and similarly Chaker's term expansion référentielle very intuitive.

\section{References}

Aikhenvald, A. 1995. 'Split ergativity in Berber languages'. St. Petersburg Journal of African Studies 4: 39-68.

Allaoua, A. 1994. 'La question du sujet nul et la fonction sujet en berbère'. Acta Orientalia 55: 7-22.

Applegate, J.R. 1970. 'The Berber languages'. In: Current Trends in Linguistics vol. 6. Linguistics in South West Asia and North Africa, ed. by Th.A. Sebeok. The Hague/Paris: Mouton, pp. 586-661.

Basset, A. 1952. La langue berbère. London: Oxford University Press.

Chaker, S. 1983. Un parler berbère d'Algérie (Kabylie). Aix-en-Provence: Université de Provence.

Chaker, S. 1984. Textes en linguistique berbère (introduction au domaine berbère). Marseille: Centre National de la Recherche Scientifique.

Chaker, S. 1988. 'Etat d'Annexation'. Encyclopédie Berbère 5, Edisud, pp. 686-695.

Creider, C.A. 1983. 'Topic-comment relations in verb-initial languages'. Journal of African Languages and Linguistics 5: 1-15.

el Aissati, A. 2001. 'Word order change in Berber'. In: Etudes berbères. Actes du 1. Bayreuth-Frankfurter Kolloquium zur Berberologie, ed. by D. Ibriszimow \& R. Vossen, pp. 33-42.

Galand, L. 1964. 'L'énoncé verbal en berbère'. Cahiers Ferdinand de Saussure 21: 33-53.

Guerssel, M. \& K. Hale 1987. Studies in Berber syntax. Cambridge, MA.: MIT.

Heath, J. 2005. A grammar of Tamashek (Tuareg of Mali). Berlin/New York: Mouton de Gruyter.

Jelinek, E. 1984. 'Empty Categories, Case and Configurationality'. Natural Language and Linguistic Theory 2: 39-76.

Kiss, K.E. 1995. Discourse Configurational Languages. Oxford: Oxford University Press.

König, C. 2006. 'Marked nominative in Africa'. Studies in Language 30(4): 655732.

Lafkioui, M. (unpublished). 'Intonation as a syntactic and semantic hierarchical organizer of sentences’. Unpublished paper presented at CALL 35, Leiden, 29-31 August 2005.

Lambrecht, K. 1994. Information Structure and Sentence Form. Topic, focus, and the mental representations of discourse referents. Cambridge: Cambridge University Press.

Lambrecht, K. \& M. Polinsky 1998. 'Typological variation in sentence constructions'. 
In: K. Singer et al. (eds.). Proceedings of the Thirty-third Annual Meeting of the Chicago Linguistic Society. Papers from the Panels. Chicago, pp. 189-206

Longacre, R.E. 1982. 'Verb ranking and the constituent structure of discourse'. Journal of the Linguistic Association of the Southwest 5: 177-202.

Longacre, R.E. 1995 'Left shifts in strongly VSO languages'. In: Word Order in Discourse, ed. by M. Noonan \& P.A. Downing, pp. 331-354.

Martinet, A. 1962. 'Le sujet comme fonction linguistique et l'analyse syntaxique du basque'. Bulletin de la Société de Linguistique 57: 73-82.

Mettouchi, A. 2003a. 'Contrastive focalization on clefts in Taqbaylit Berber'. In: Proceedings of IOP 2003 Interfaces Prosodiques, Nantes, 27-29 March 2003, ed. by A. Mettouchi \& G. Ferré. pp. 143-148.

Mettouchi, A. 2003b. 'Focalisation contrastive et structure de 1'information en kabyle (berbère)'. In: Mémoires de la Société de Linguistique de Paris "Fonctions et moyens d'expression de la focalisation », ed. by J. François and A. Lacheret, Paris/ Louvain: Peeters, pp. 81-97.

Mettouchi, A. 2004 'Diathesis, Aspect and Stativity in Taqbaylit Berber'. In: Nouvelles Etudes Berbères, ed. by K. Naït-Zerrad, R. Vossen and D. Ibriszimow. Cologne: Köppe, pp. 95-109.

Mettouchi, A. 2005. 'Discourse-configurationality and the encoding of semantic macro-roles in Taqbaylit Berber: noun phrase, personal affixes and clitics'. In: Studi Afroasiatici. XI Incontro Italiano di linguistica camitosemitica, ed. by A. Mengozzi. Milan: Francoangeli, 83-96.

Mettouchi, A. 2005b. '„Sujet“" postverbal et état d'annexation en kabyle (berbère)'. Faits de Langues 27 'Les Langues Chamito-Sémitiques'.

Mettouchi, A. to appear a. 'Le problème du sujet en berbère'. In: A. Donabédian (ed.), Le sujet. (Cahiers de Linguistique de l'INALCO). Paris: Publications des Langues' $\mathrm{O}$.

Mettouchi, A. to appear b. "Case-marking, Syntactic domains and Information structure in Kabyle (Berber)." In: Interaction of syntax and morphology: case studies in Afroasiatic, ed. by E. Shay \& Z. Frajzyingier, Amsterdam, Philadelphia: Joh Benjamins.

Mettouchi, A. 2007. 'Word order in conversational Taqbaylit Berber. Preposed and postposed subjects'. In: From beyond the Mediterranean. 7. Internationaler Semitohamitisten-Kongre $\beta$ [Semitica et Semitohamitica Berolinensia, vol. 5], ed. by. R. Voigt. Herzogenrath: Shaker.

Mithun, M. 1987. 'Is basic word order universal?' In: Coherence and Grounding in Discourse, ed. by R. Tomlin. Amsterdam, Philadelphia: Benjamins, pp. 281-328.

Payne, D.L. 1995. 'Verb initial languages and information order'. In: Word Order in Discourse, ed. by M. Noonan \& P.A. Downing. Amsterdam, Philadelphia: Benjamins, pp. 449-486.

Sasse, H.-J. 1984. 'Case in Cushitic, Semitic and Berber'. In: Current Progress in AfroAsiatic Linguistics. Papers of the Third International Hamito-Semitic Congress, London, 1978, ed. by J. Bynon. Amsterdam: Benjamins, pp. 111-125. 
Sasse, H.-J. 1987. 'The thetic-categorical distinction revisited'. Linguistics 25: 511580 .

Stroomer, H. 2002. Tashelhiyt Berber folktales from Tazerwalt (South Morocco). A reanalysis of Hans Stumme's Tazerwalt texts with an English translation. Cologne: Köppe.

Tomlin, R. \& R. Rhodes 1992. 'Information distribution in Ojibwa'. In: Pragmatics of word order flexibility, ed. by D. Payne. Amsterdam/Philadelphia: Benjamins, pp. $117-135$ 